\title{
1 A-type FHFs mediate resurgent currents through TTX-resistant voltage-gated sodium
}

\section{2 channels}

3 Yucheng Xiao ${ }^{1 *}$, Jonathan W. Theile ${ }^{2}$, Agnes Zybura ${ }^{3}$, Yanling Pan ${ }^{1}$, Zhixin Lin $^{2}$, Theodore R.

4 Cummins $^{1 *}$

${ }^{1}$ Biology department, School of Science, Indiana University Purdue University Indianapolis, Indianapolis, IN 46202, Indiana University School of Medicine, Indianapolis, IN 46202, USA.

10 *corresponding authors: Yucheng Xiao, yuchxiao@indiana.edu; Theodore R. Cummins,

11 trcummin@iu.edu. 
13 Abstract

14 Resurgent currents $\left(I_{\mathrm{NaR}}\right)$ produced by voltage-gated sodium channels are required for many neurons to

15 maintain high-frequency firing, and contribute to neuronal hyperexcitability and disease pathophysiology.

16 Here we show, for the first time, that $I_{\mathrm{NaR}}$ can be reconstituted in a heterologous system by co-expression

17 of sodium channel $\alpha$-subunits and A-type fibroblast growth factor homologous factors (FHFs).

18 Specifically, A-type FHFs induces $I_{\mathrm{NaR}}$ from Nav1.8, Nav1.9 tetrodotoxin-resistant neuronal channels

19 and, to a lesser extent, neuronal Nav1.7 and cardiac Nav1.5 channels. Moreover, we identified the N-

20 terminus of FHF as the critical molecule responsible for A-type FHFs-mediated $I_{\text {NaR. }}$. Among the FHFs,

21 FHF4A is the most important isoform for mediating Nav1.8 and Nav1.9 $I_{\mathrm{NaR}}$. In nociceptive sensory

22 neurons, FHF4A knockdown significantly reduces $I_{\mathrm{NaR}}$ amplitude and the percentage of neurons that

23 generate $I_{\mathrm{NaR}}$, substantially suppressing excitability. Thus, our work reveals a novel molecular

24 mechanism underlying TTX-resistant $I_{\mathrm{NaR}}$ generation and provides important potential targets for pain

25 treatment.

26 Key words: sodium channel; resurgent currents; FHF; Nav $\beta 4$; dorsal root ganglion 


\section{Introduction}

35 Voltage-gated sodium channels (VGSCs) are crucial determinants of action potentials in almost all excitable tissues. VGSCs are composed of a functional pore-forming $\alpha$-subunit associated with auxiliary

$37 \beta$-subunits (Catterall et al., 2005). VGSCs also interact with other intracellular proteins, such as fibroblast 38 growth factor homologous factors (FHFs) and calmodulin (Catterall et al., 2005; Wildburger et al., 2015).

39 Although the $\alpha$-subunit is sufficient to produce a functional VGSC, interacting partners can influence

40 multiple properties of the $\alpha$-subunits, regulating neuronal excitability (Namadurai et al., 2015). One of the

41 most striking influences is generation of resurgent sodium currents ( $\left.I_{\mathrm{NaR}}\right)$ (Lewis and Raman, 2014).

$42 \quad I_{\mathrm{NaR}}$ were originally observed in cerebellar Purkinje neurons (Raman and Bean, 1997), and have been 43 identified in cerebellum, brainstem, trigeminal ganglia and dorsal root ganglion (DRG) neurons (Afshari

44 et al., 2004, Enomoto et al., 2006; Kim et al., 2010). $I_{\mathrm{NaR}}$ can enhance high-frequency firing in many 45 neurons (Raman and Bean, 1997, Xie et al., 2016), and aberrant $I_{\mathrm{NaR}}$ have been implicated in multiple

46 human diseases including pain disorders (Jarecki et el., 2010; Patel et al., 2016; Theile et al., 2011;

47 Tanaka et al., 2016). Unlike classic sodium currents that are activated during the depolarizing phase of

48 action potentials, $I_{\mathrm{NaR}}$ are atypical sodium currents evoked during the repolarizing phase. Nav $\beta 4$ has been

49 implicated as a major contributor to $I_{\mathrm{NaR}}$ generation (Grieco et al., 2005; Barbosa et al., 2015; Cannon and

50 Bean, 2010). The most direct evidence supporting the Nav $\beta 4$ mechanism is that a short peptide derived

51 from the C-terminal tail of Nav $\beta 4$ can reconstitute the $I_{\mathrm{NaR}}$. However, the Nav $\beta 4$ mechanism remains

52 controversial for at least two reasons: (1) Nav $\beta 4$ knockout or knockdown does not abolish $I_{\mathrm{NaR}}$ in central

53 (White et al., 2019; Ransdell et al., 2017) or peripheral neurons (Xiao et al., 2019), but rather results in

54 only partial to no reduction of $I_{\mathrm{NaR}}$; and (2) importantly, coexpression of full-length Nav $\beta 4$ with VGSC $\alpha$ -

55 subunits fails to reconstitute $I_{\mathrm{NaR}}$ in heterologous systems. Therefore, other molecular mechanisms for $I_{\mathrm{NaR}}$ 56 generation remain to be uncovered. 
57 FHFs are widely distributed throughout the CNS/PNS. They represent an important group of auxiliary

58 VGSC subunits that influence neuronal excitability. FHF is a subfamily of the fibroblast growth factor

59 (FGF) superfamily. They can bind to the VGSC C-terminal tails and can modulate VGSCs functional

60 properties, trafficking and axonal localization (Liu et al., 2001; Goetz et al., 2009; Wittmack et al., 2004;

61 Lou et al., 2005; Wang et al., 2011b). There are two main types of FHFs: A-type and B-type. The former

62 has four isoforms (FHF1A - FHF4A). There is emerging evidence that FHFs regulate $I_{\mathrm{NaR}}$ generation in

63 neurons. In DRG neurons, overexpression of FHF2A and FHF2B decreases and increases Nav1.6 $I_{\mathrm{NaR}}$,

64 respectively (Barbosa et al., 2017). In contrast FHF4A, which has high sequence similarity to FHF2A, has

65 been proposed to directly mediate $I_{\mathrm{NaR}}$ generation by Nav1.6. FHF4 knockout significantly reduced $I_{\mathrm{NaR}}$

66 in Purkinje neurons, which is mainly carried by Nav1.6, and a peptide corresponding to FHF4A residues

67 50-63 induced robust $I_{\mathrm{NaR}}$ in CA3 neurons (White et al., 2019). However, both FHF2A and FHF4A have

been shown to induce accumulation of rapid onset long-term inactivation when coexpressed with Nav1.6

in heterologous systems (Venkatesan et al., 2014; Dover et al., 2010). In addition, the reduction in

73 In this study, we report that A-type FHFs directly mediate resurgent sodium current generation in Nav1.8

74 and Nav1.9 sensory neuron VGSCs, and show for the first time that $I_{\mathrm{NaR}}$ can be reconstituted in

75 heterologous systems by coexpressing full-length A-type FHFs with VGSC $\alpha$-subunits. These FHF-

76 mediated $I_{\mathrm{NaR}}$ are independent of Nav $\beta 4$. The novel FHF-mediated $I_{\mathrm{NaR}}$ could be fully reproduced by the

77 amino acids 2-21 from the A-type FHF N-terminus. We also show that while FHF2A could induce small

$78 I_{\mathrm{NaR}}$ with Nav1.5 and Nav1.7, FHF4A did not induce Nav1.5, Nav1.6 or Nav1.7 $I_{\mathrm{NaR}}$ in heterologous

79 expression systems. We further show that reduction of FHF4A-mediated TTX-resistant $I_{\mathrm{NaR}}$ substantially

80 downregulated excitability of nociceptive DRG neurons. Because Nav1.7 - Nav1.9 are predominantly

81 expressed in neurons of DRG and trigeminal ganglia, and are crucial for pain perception and 
82 transmission (Cummins et al., 2004; Cox et al., 2006; Huang et al., 2014; Dib-Hajj et al., 2015; Huang et

83 al., 2013; Cummins et al., 2007; Dib-Hajj et al., 2010), our work not only uncovers a novel mechanism of

$84 \quad I_{\mathrm{NaR}}$ generation in sensory neurons, but also identifies an exciting target for the development of new pain

85 treatments.

86 


\section{Results}

A-type FHFs mediate $I_{\mathrm{NaR}}$ in heterologously expressed Nav1.8 and Nav1.9. A-type FHFs can

modulate TTX-sensitive VGSC inactivation and $I_{\mathrm{NaR}}$ (White et al., 2019; Barbosa et al., 2017; Yan et al., 2014), however it is unknown if A-type FHFs impact the functional properties of the TTX-resistant sodium channels Nav1.8 and Nav1.9. Therefore, we first asked whether FHF2A and FHF4A, which are widely expressed in DRG neurons, modulate sodium currents in cells expressing recombinant Nav1.8 and Nav1.9. As previously shown in heterologous systems (Xiao et al., 2019; Lin et al., 2016), Nav1.8 generated a slow-inactivating TTX-resistant current, while Nav1.9 produced an ultra-slow-inactivating TTX-resistant current that activated at hyperpolarized potentials (Fig. 1 $a, d$ ). Here we show that FHF2A, FHF2B and FHF4A, when coexpressed with Nav1.8, shifted the voltage-dependence of activation by $>7$ $\mathrm{mV}$ in the negative direction, and shifted the voltage dependence of steady-state inactivation by $>15 \mathrm{mV}$ in the positive direction (Fig. 1b; Table 1). FHF2A, FHF2B and FHF4A also accelerated recovery rate from inactivation of Nav1.8 (Fig. 1c). When coexpressed with Nav1.9, FHF2A and FHF4A, but not FHF2B, positively shifted the voltage-dependence of steady-state inactivation by $\sim 10 \mathrm{mV}$. Distinct from Nav1.8, none of the three FHF isoforms altered the voltage-dependence of activation or rate for recovery from inactivation of Nav1.9 (Fig. 1e, $f$; Table 1), suggesting that FHFs differentially regulate TTXresistant VGSCs.

We next examined the effects of FHFs on $I_{\mathrm{NaR}}$ generation. FHF2A and FHF4A induced robust $I_{\mathrm{NaR}}$ from Nav1.8 and Nav1.9 in HEK293 cells (Fig. 2a-h). However, under control conditions and with coexpression of FHF2B, the repolarization pulses only elicited classic tail currents, which arise nearly

107 instantaneously and decay rapidly, in Nav1.8 and Nav1.9 (Fig. $2 a$ (left), $b, e$ (left) and f). This is the first

108 demonstration of $I_{\mathrm{NaR}}$ generation in a heterologous expression system without inclusion of an exogenous 109 peptide in the intracellular solution. The FHF-mediated Nav1.8 $I_{\text {NaR }}$ peaked at -20 to $-10 \mathrm{mV}$ and could be observed at repolarization pulses ranging from +5 to $-80 \mathrm{mV}$, while the FHF-mediated Nav1.9 $I_{\mathrm{NaR}}$ displayed a more hyperpolarized voltage dependence, peaking at $-85 \mathrm{mV}$ and observed at repolarizing 
112 potentials ranging from -55 to $-100 \mathrm{mV}$ (Fig. $2 e, g$ ). Moreover, the Nav1.8 $I_{\mathrm{NaR}}$ induced by FHF4A were

113 four-fold larger than those by FHF2A (Fig. 2C, relative amplitudes of the peak transient current: FHF2A:

$1141.5 \% \pm 0.2 \%$; FHF4A: $5.9 \% \pm 0.4 \%$ ), and the Nav1.9 $I_{\mathrm{NaR}}$ mediated by FHF4A was two-fold larger than

115 those induced by FHF2A (FHF2A: $14.8 \% \pm 3.9 \%$; FHF4A: $32.6 \% \pm 3.0 \%$ ). The kinetics of Nav1.8 $I_{\text {NaR }}$

116 mediated by A-type FHF are slow, with a slow onset and slow decay. The time to peak and the decay time

117 constant for the FHF4A-mediated $I_{\mathrm{NaR}}$ elicited at $-20 \mathrm{mV}$ were $9.63 \pm 0.61 \mathrm{~ms}$ and $85.97 \pm 5.29 \mathrm{~ms}$,

118 respectively (Fig. $2 d$ ), similar to the TTX-resistant $I_{\text {NaR }}$ previously recorded from DRG neurons (19). In

119 contrast, FHF-mediated Nav1.9 $I_{\mathrm{NaR}}$ exhibit fast onset and decay kinetics. At $-70 \mathrm{mV}$, near the

120 physiological resting membrane potential of DRG neurons, the time to peak and the decay time constant

121 for FHF4A-mediated Nav1.9 $I_{\mathrm{NaR}}$ were $1.92 \pm 0.12 \mathrm{~ms}$ and $8.09 \pm 1.31 \mathrm{~ms}$, respectively (Fig. $2 h$ ). It is

122 noteworthy that Nav1.9 produced a non-decaying inward current following the $I_{\mathrm{NaR}}$ (control, Fig. 2e-f).

123 This non-decaying current activated extremely slowly during 100 ms voltage pulses, occurred in the

absence and presence of FHFs, and persisted even when the repolarization pulse was extended to $1000 \mathrm{~ms}$

(Figure 2-figure supplement 1a). Importantly, the current-voltage curve almost completely overlapped

127 inactivation curves (Figure 2-figure supplement $1 b-d$ ). Since "window current" typically results in

128 persistent current (Attwell et al., 1979), we suggest that these non-decaying currents result from a slow recovery from inactivation of Nav1.9 persistent currents. Regardless, these data indicate for the first time that Nav1.9 channels can generate a novel $I_{\mathrm{NaR}}$ distinct from those generated by Nav1.8 and TTXsensitive VGSCs. 
$9.0 \% \pm 2.3 \%$; FHF3A, $5.8 \% \pm 1.1 \%)$. These $I_{\mathrm{NaR}}$ displayed a voltage dependence of activation similar to those observed with FHF2A and FHF4A (Fig. 1b-f). Based on the relative amplitudes of the generated $I_{\mathrm{NaR}}$, the rank order of the ability of the four A-type FHFs to mediate Nav1.8 $I_{\mathrm{NaR}}$ is FHF4A $>$ FHF1A $>$

140 FHF3A $\approx$ FHF2A, while the rank order for Nav1.9 $I_{\text {NaR }}$ generation is FHF4A $>$ FHF2A $>$ FHF1A $>$

141 FHF3A.

F2A/F4A peptides fully reconstituted $\boldsymbol{I}_{\mathrm{NaR}}$. FHF2A, but not FHF2B, induces robust $I_{\mathrm{NaR}}$ from Nav1.8 and Nav1.9 (Fig. 2b,f). Intriguingly, FHF2A and FHF2B differ only in their N-terminus due to the alternative splicing of exon 1 (Fig. 3a). Moreover, a peptide derived from amino acids 2-21 of the FHF2A $\mathrm{N}$-terminus has been shown to induce long-term inactivation of Nav1.6 channels (Dover et al., 2010). We hypothesized that the same region of the N-terminal tail is the critical molecular component necessary for

$147 I_{\mathrm{NaR}}$ induction by A-type FHFs. To test this hypothesis, we intracellularly applied a 20-residue peptide

148 (F2A or F4A), derived from the N-terminal residues 2-21 of FHF2A or FHF4A. We asked whether these

149 peptides could reconstitute A-type FHF-mediated $I_{\mathrm{NaR}}$ observed with coexpression of full-length

150 FHF2A/FHF4A (Fig. $3 a$ ). In the presence of $1 \mathrm{mM} \mathrm{F} 2 \mathrm{~A}$ or F4A, both Nav1.8 and Nav1.9 generated $I_{\text {NaR. }}$.

151 The relative amplitudes were $1.5 \% \pm 0.1 \%$ and $2.5 \% \pm 0.4 \%$ in Nav1.8 at $-15 \mathrm{mV}$ (Fig. $3 b$, c), and $18.0 \%$

$152 \pm 3.1 \%$ and $10.3 \% \pm 1.4 \%$ in Nav1.9 at $-85 \mathrm{mV}$, respectively (Fig. $3 f$, g). The $I_{\text {NaR }}$ retained the kinetics

153 and voltage dependence of activation as observed with full-length FHF2A and FHF4A (Fig. 2c, g). On the

154 other hand, both F2A and F4A significantly decreased the inactivation time constant of the transient

155 currents of Nav1.8 and Nav1.9 evoked by a 20 -ms pre-pulse to $+30 \mathrm{mV}$ (Fig. $3 d, g$ ), suggesting that both

156 F2A and F4A serve as open channel blockers of Nav1.8 and Nav1.9. This is consistent with the previous

157 reports that F2A induces open-channel block in Nav1.5 and Nav1.6 (Venkatesan et al., 2014; Dover et al., 158 2010).

159 To further investigate the roles of these peptides in $I_{\mathrm{NaR}}$ generation, we employed a F2A mutant (Dover et 160 al., 2010) in which five positively charged residues (K1/R2/R3/R4/K5) are substituted with the neutral residue glutamine (5Q, Fig. $3 a$ ). In Fig. $3 b$,e, the mutant 5Q peptide failed to induce $I_{\mathrm{NaR}}$ in Nav1.8 or 
162 Nav1.9: the currents elicited during the repolarization pulse almost overlapped in the absence (control)

163 and presence of $1 \mathrm{mM} 5 \mathrm{Q}$. Consistent with this finding, the transient current inactivated more slowly at

$164+30 \mathrm{mV}$ with 5Q than with F2A (Fig. 3d,g). Interestingly, the transient current still inactivated faster than

165 under control conditions, suggesting that 5Q may still bind to VGSCs, but with lower affinity compared

166 to F2A. These results suggest that the five positively charged residues in A-type FHFs are critical

167 components for inducing $I_{\mathrm{NaR}}$.

FHF4A mediated Nav1.8 $I_{\mathrm{NaR}}$ in sensory neurons. DRG neurons show expression of FHF4A along with Nav1.8 and Nav1.9. Our results in heterologous systems showed that FHF4A was most capable among the A-type FHF isoforms at inducing $I_{\mathrm{NaR}}$ with Nav1.8 and Nav1.9. Therefore, we next asked if

171 FHF4A mediates $I_{\mathrm{NaR}}$ in primary neurons. We are able to isolate Nav1.9 $I_{\mathrm{NaR}}$ in DRG neurons (Fig. 4).

172 However, while these unique $I_{\mathrm{NaR}}$ are strikingly similar to those recorded when A-type FHFs are co-

173 expressed with Nav1.9 in HEK293 cells, the endogenous Nav1.9 $I_{\mathrm{NaR}}$ are only evident in a small subset of

174 DRG neurons. On the other hand, in our previous work Nav1.8 type $I_{\mathrm{NaR}}$ could be recorded from the

175 majority of DRG neurons expressing endogenous Nav1.8 currents and almost all DRG neurons

176 expressing recombinant Nav1.8 (Xiao et al., 2019). We therefore next focused on interrogating the role of

177 Nav1.8 $I_{\mathrm{NaR}}$ in DRG neurons.

178 Consistent with our previous observation (Xiao et al., 2019), 13/14 small diameter DRG neurons

179 transfected with a scrambled shRNA were found to generate Nav1.8 $I_{\mathrm{NaR}}$. The largest $I_{\mathrm{NaR}}$ was attained at

$180-15 \mathrm{mV}$, with an average relative amplitude of $2.1 \% \pm 0.3 \%$ of the peak transient TTX-resistant sodium

181 current. The time to peak and the decay time constant for the current elicited at $-15 \mathrm{mV}$ were $45.0 \pm 4.4$

$182 \mathrm{~ms}$ and $546.3 \pm 43.2 \mathrm{~ms}$, respectively. These results were identical to those seen in DRG neurons, without

183 scrambled shRNA, in our previous work (Xiao et al., 2019), suggesting that the scrambled shRNA did not

184 alter Nav1.8 $I_{\mathrm{NaR}}$. The efficiency of FHF4shRNA-mediated knockdown was determined using a

185 monoclonal antibody specific to FHF4, which has been validated in heterologous systems in our

186 laboratory. In Fig. 5a,b, FHF4shRNA reduced FHF4 expression by $73.1 \%(\mathrm{p}<0.0001)$. FHF4 
knockdown did not significantly alter current density, voltage dependence of activation or recovery rate from inactivation of Nav1.8 currents in DRG neurons, but caused a hyperpolarizing shift of $12 \mathrm{mV}$ in the voltage dependence of steady-state inactivation ( $\mathrm{p}<0.0001$; Fig. $5 c-e$; Table 2). FHF4 knockdown considerably decreased the proportion of DRG neurons producing $I_{\mathrm{NaR}}(9 / 18$ cells $v s$ 13/14 scramble cells; $\mathrm{p}=0.0095, \chi^{2}$ test; Fig. $5 g$ ). Furthermore, in those DRG neurons with $I_{\mathrm{NaR}}$, FHF4 knockdown did not

192 modify the voltage dependence of activation of Nav1.8 $I_{\mathrm{NaR}}$, but reduced the relative amplitude by about

$19342 \%$ (FHF4shRNA, $1.2 \% \pm 0.2 \%$; $<0.05$; Fig. $5 h$ ). Although our previous work showed that Nav $\beta 4$ can

194 contribute to generation of Nav1.8 $I_{\mathrm{NaR}}$ in DRG neurons (Xiao et al., 2019), the reduction here was Nav $\beta 4$

195 independent because FHF4 knockdown did not significantly change Nav $\beta 4$ expression level in our

196 immunostaining experiments (Figure 5-figure supplement 1). Therefore, our data indicate that FHF4A is a

197 major producer of Nav1.8 $I_{\mathrm{NaR}}$ in small diameter DRG neurons. The remaining $I_{\mathrm{NaR}}$ after FHF4-

knockdown are possibly mediated by residual FHF4A, endogenous FHF2A or endogenous Nav $\beta 4$.

199 FHF4A-mediated Nav1.8 $\boldsymbol{I}_{\mathrm{NaR}}$ regulated sensory neuron excitability. We next explored the impact of

200 FHF4A-mediated $I_{\mathrm{NaR}}$ on neuronal excitability. Previous studies have shown that FHFs profoundly

201 modulate the activities of TTX-sensitive VGSCs in DRG neuron (Barbosa et al.; 2017, Venkatesan et al.,

202 2014; Dover et al., 2010), therefore we measured excitability of small diameter DRG neurons in the

203 presence of $500 \mathrm{nM}$ TTX, which blocks all TTX-sensitive VGSCs and removes this confounding variable.

204 FHF4 knockdown did not change resting membrane potential, input resistance or current threshold of

205 action potential firing (scramble, $-54.9 \pm 1.1 \mathrm{mV}, 463.3 \pm 38.5 \mathrm{M} \Omega, 1.26 \pm 0.21 \mathrm{nA}$; FHF4shRNA, -57.2

$206 \pm 1.6 \mathrm{mV}, 548.7 \pm 66.9 \mathrm{M} \Omega, 1.22 \pm 0.14 \mathrm{nA} ; \mathrm{p}>0.05$; Fig. $6 a-c)$, but narrowed single evoked action

207 potentials. The average action potential durations measured under scramble and FHF4shRNA were 17.94

$208 \pm 2.63 \mathrm{~ms}$ and $10.54 \pm 1.19 \mathrm{~ms}(\mathrm{p}=0.0153$; Fig. $6 d)$, respectively. With 2-s injected currents greater than

$209300 \mathrm{pA}$, the FHF4-knockdown DRG neurons displayed significantly fewer action potentials than the

210 scramble-treated neurons (Fig. 6e,f). 
211 We then tested whether F4A peptide could reverse the FHF4A knockdown-mediated effects on $I_{\mathrm{NaR}}$ and

212 neuronal excitability. Intracellular application of $1 \mathrm{mM} \mathrm{F} 4 \mathrm{~A}$ did not significantly alter current density,

213 voltage dependence of activation, steady-state inactivation or recovery rate from inactivation of Nav1.8

214 currents in FHF4shRNA-treated DRG neurons (Fig. 6g-i; Table 2). Although F4A peptide did not reverse

215 the negative shift in the voltage dependence of steady-state inactivation caused by FHF4 knockdown

216 (shown in Fig. 5d), F4A peptide did rescue the FHF4-knockdown-mediated decrease in $I_{\text {NaR: }}$ 10/10 DRG

217 neurons tested yielded Nav1.8 $I_{\mathrm{NaR}}\left(\mathrm{p}=0.0066 ; \chi^{2}\right.$ test; Fig. $\left.6 j\right)$. The average relative amplitude measured

218 at $-15 \mathrm{mV}$ increased from $1.2 \% \pm 0.2 \%$ (FHF4shRNA) to $2.7 \% \pm 0.4 \%$ (F4A; $\mathrm{p}=0.0027$; Fig. $6 \mathrm{k}$ ),

219 similar to the amplitude yielded under the scramble condition. F4A peptide did not change the resting

220 membrane potential, input resistance or current threshold in FHF4shRNA-treated DRG neurons (+F4A, -

$22154.8 \pm 2.3 \mathrm{mV}, 502.8 \pm 92.9 \mathrm{M} \Omega, 1.19 \pm 0.15 \mathrm{nA} ; \mathrm{p}>0.05 v s$ scramble and FHF4shRNA; Fig. $6 b, c)$, but

222 significantly broadened action potentials (average duration of $14.76 \pm 1.22 \mathrm{~ms} ; \mathrm{p}=0.0233$; Fig. $6 d$ ). F4A

223 peptide increased the number of action potentials elicited by 2-s injected currents of 400 pA (Fig. $6 e$ ).

224 Finally, the FHF4shRNA-transfected DRG neurons treated with F4A peptide could fire action potentials

225 at almost the same frequency as the scramble-transfected neurons (Fig. 6f), demonstrating that the loss of

226 sensory neuron excitability by FHF4 knockdown can be rescued by F4A. Therefore, our data clearly

227 illustrate that A-type FHF is a critical molecule in small diameter DRG neurons and that A-type FHF

228 determines neuronal excitability via $I_{\mathrm{NaR}}$ generation.

229 Navß4 does not elicit Nav1.9 $\boldsymbol{I}_{\mathrm{NaR}}$. The Nav1.9 $I_{\mathrm{NaR}}$ identified in HEK293 cells cotransfected with

230 Nav1.9 and A-type FHFs is distinct from the $I_{\text {NaR }}$ observed with other VGSCs. As Nav $\beta 4$ has been shown

231 to induce $I_{\mathrm{NaR}}$ in all of the other VGSC isoforms (Nav1.1 - Nav1.8), we asked if Nav $\beta 4$ also induces $I_{\mathrm{NaR}}$

232 with Nav1.9. Multiple studies have failed to reconstitute $I_{\mathrm{NaR}}$ in heterologous systems by coexpressing

233 full-length Nav $\beta 4$ with VGSC $\alpha$-subunits $(12,39,40)$. However, a short peptide (KKLITFILKKTREK)

234 derived from the Nav $\beta 4$ C-terminus can induce $I_{\mathrm{NaR}}$ generation in heterologous expression systems and

235 also in primary neurons (Grieco et al., 2005; Barbosa et al., 2015). Here we intracellularly applied Nav $\beta 4$ 
peptide $(200 \mu \mathrm{M})$ to investigate if Nav1.9 expressed in HEK293 cells could utilize the C-terminus of were observed with the Nav $\beta 4$ peptide ( $\mathrm{p}>0.05$; Fig. $7 a, b)$, indicating that Nav $\beta 4$ is not capable of mediating $I_{\mathrm{NaR}}$ in Nav1.9.

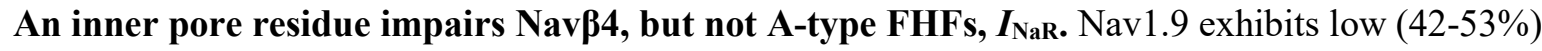
sequence similarity to other mammalian VGSC subtypes. We hypothesized that non-conserved pore residues, especially positive residues, might prevent the positively charged Nav $\beta 4$ peptide from binding to the Nav1.9 inner pore. Sequence analysis identified K799, residing in the II-S6 segment of Nav1.9, as a promising candidate for such prevention (Fig. 8a). The corresponding residue in all other VGSC isoforms is an asparagine. As described previously (Lin et al., 2016), the K799N mutation does not significantly alter Nav1.9 gating properties (Fig. 8b; Table 3). Interestingly, the K799N mutation greatly enhanced the

247 ability of $\mathrm{Nav} \beta 4$ peptide $(200 \mu \mathrm{M})$ to mediate Nav1.9 $I_{\mathrm{NaR}}$ in response to a depolarizing voltage of +100

$248 \mathrm{mV}$. Fig. $8 c$ shows that Nav $\beta 4$ peptide mediated $I_{\mathrm{NaR}}$ in $\mathrm{K} 799 \mathrm{~N}$ channels with a fast onset/decay kinetics and a hyperpolarized voltage dependence of activation similar to A-type FHF-mediated Nav1.9 $I_{\mathrm{NaR}}$. The relative amplitude is $6.6 \% \pm 0.5 \%$ at $-85 \mathrm{mV}$ (Fig. $8 d$ ). Intriguingly, the $\mathrm{K} 799 \mathrm{~N}$ mutation did not alter F2A-mediated $I_{\mathrm{NaR}}(\mathrm{Nav} 1.9,17.0 \% \pm 2.5 \% ; \mathrm{K} 799 \mathrm{~N}, 18.1 \% \pm 3.5 \% ; \mathrm{p}>0.05 ;$ Fig. $8 e, f)$.

To further confirm the role of this residue in modulating VGSCs $I_{\mathrm{NaR}}$, we constructed reverse mutations at corresponding positions in Nav1.5 and Nav1.7 (Fig. 8a). The reverse mutation N927K did not influence

254 gating properties of Nav1.5 (Fig. 8b; Table 3), but reduced Nav1.5 $I_{\mathrm{NaR}}$ induced by the presence of 200

$255 \mu \mathrm{M}$ Navß4 peptide by $92 \%(\mathrm{Nav1.5}, 17.2 \% \pm 2.1 \%$; $927 \mathrm{~K}, 1.3 \% \pm 0.1 \% ; \mathrm{P}<0.0001 ;$ Fig. $8 g, h)$. A

256 substantial reduction ( $85 \%$ ) was also observed for the N945K mutation in Nav1.7 (Figure 8-figure

257 supplement 1). In contrast, the N927K mutation did not impair the ability of Nav1.5 to generate $I_{\mathrm{NaR}}$ 258 mediated by full-length FHF2A (Nav1.5, 0.24\% $\pm 0.03 \%$; N927K, $0.23 \% \pm 0.03 \%$; p > 0.05; Fig. 8i,j).

259 Collectively, these results indicate that the residue at position 799 in Nav1.9 is involved in VGSC interaction with Navß4. Although K799 in Nav1.9 is a major determinant of Nav1.9 resistance to the 
261 Navß4 peptide, it may not be the only factor involved in Nav1.9 resistance. Furthermore, because changes

262 at this position did alter A-type FHF mediated $I_{\mathrm{NaR}}$, we propose that A-type FHFs and Nav $\beta 4$ do not share

263 identical binding determinants in the pore of VGSCs.

264 FHF2A mediated Nav1.5 and Nav1.7, but not Nav1.6, $I_{\mathrm{NaR}}$ in heterologous system. Finally, we asked

265 if other VGSC isoforms share the FHF mechanism of $I_{\mathrm{NaR}}$ generation. We studied Nav1.5, Nav1.6 and

266 Nav1.7, because they are coexpressed with FHF2A or FHF4A in cardiac myocytes and neurons (Li et al.,

267 2002; Wang et al., 2011a; Yan et al., 2014; Barbosa et al., 2017; White et al., 2019). Coexpression of

268 FHF2A with Nav1.5 or Nav1.7 induced $I_{\text {NaR }}($ Fig. $9 a-f)$, with a voltage dependence of activation more

269 negative than Nav1.8 but more positive than Nav1.9 $I_{\mathrm{NaR}}($ Fig. $1 c, f)$. Maximal $I_{\mathrm{NaR}}$ were attained at near -

$27040 \mathrm{mV}$. The average relative amplitudes were at least 6-fold smaller (Nav1.5, 0.22\% $\pm 0.02 \%$; Nav1.7,

$2710.27 \% \pm 0.02 \%$ ) than Nav1.8 and Nav1.9 $I_{\text {NaR. }}$ The time to peak and the decay time constant for the

272 FHF2A-mediated Nav1.5 $I_{\mathrm{NaR}}$ were $10.2 \pm 1.3 \mathrm{~ms}$ and $120.8 \pm 19.6 \mathrm{~ms}$ at $-40 \mathrm{mV}$, respectively (Fig. 9i).

273 FHF2A-mediated Nav1.7 $I_{\mathrm{NaR}}$ displayed a similar rise and decay kinetics to Nav1.5 $I_{\mathrm{NaR}}$ (Fig. 9i).

274 However, neither FHF2B nor FHF4A generated $I_{\mathrm{NaR}}$ in Nav1.5 and Nav1.7 (Fig. $9 b, e$ ). Neither FHF2A

275 nor FHF4A induced generation of $I_{\text {NaR }}$ with Nav1.6 (Fig. 8g, $h$ ). However, coexpression of FHF4A with

276 Nav1.6 elicited long-term inactivation of Nav1.6 in ND7/23 cells (Figure 10), similar to that previously

277 shown for co-expression of FHF2A with Nav1.6 in HEK293 cells (Rush et al., 2006). Furthermore,

278 intracellular application of the F4A peptide did not induce $I_{\mathrm{NaR}}$, only long-term inactivation similar to that

279 induced by full-length FHF4A (Figure 10).

\section{Discussion}

281 Resurgent sodium currents are critical regulators of central and peripheral neuron excitability. In this

282 study, we identify A-type FHFs as direct mediators of TTX-resistant VGSC $I_{\text {NaR. }}$ We show, for the first

283 time, that coexpression of only two proteins, a full-length A-type FHF and a VGSC $\alpha$-subunit, is

284 sufficient in heterologous systems to reconstitute $I_{\text {NaR }}$. We show that short peptides derived from A-type 
FHF N-termini, the precise residues that induce long-term inactivation in other VGSCs (Venkatesan et al., 2014) can fully replicate the Nav1.8 and Nav1.9 TTX-resistant $I_{\mathrm{NaR}}$. Importantly, we implicate A-type

287 FHFs as major drivers of TTX-resistant $I_{\mathrm{NaR}}$ in nociceptive DRG neurons.

288 We also identified a novel TTX-resistant Nav1.9 $I_{\text {NaR }}$, which shows unique biophysical properties. The voltage dependence of activation of Nav1.9 $I_{\mathrm{NaR}}$ is $>40 \mathrm{mV}$ more negative than previously described $I_{\mathrm{NaR}}$ and these Nav1.9 currents exhibit faster onset/decay kinetics than Nav1.8 $I_{\text {NaR }}$. The ratio of $I_{\text {NaR }}$ to peak transient current is at least fivefold larger in Nav1.9 than in other VGSC isoforms. This is likely due to the extremely slow fast-inactivation of Nav1.9, because destabilizing VGSC fast-inactivation by disease mutations or toxins enhances $I_{\mathrm{NaR}}$ generation (Grieco and Raman, 2004; Jarecki et al., 2010; Bant et al., 294 2013; Xiao et al., 2019). Interestingly, while coexpression of A-types FHFs resulted in consistent Nav1.9 $295 I_{\mathrm{NaR}}$ in HEK293 cells, only a small fraction of rodent DRG neurons exhibited Nav1.9 $I_{\mathrm{NaR}}$. This might due 296 to differences between rodent and human Nav1.9, or as a result of the complex modulation of Nav1.9 $I_{\mathrm{NaR}}$ 297 in sensory neurons.

298 Our data reveal a novel mechanism of $I_{\mathrm{NaR}}$ generation independent of Nav $\beta 4$. This is surprising, because a 299 substantial number of studies have implicated Nav $\beta 4$ as a major determinant of $I_{\mathrm{NaR}}$ in multiple VGSC 300 subtypes (Grieco et al., 2005; Jarecki et al., 2010; Bant and Raman, 2010; Lewis and Raman, 2011;

301 Miyazaki et al., 2014; Barbosa et al., 2015; Patel et al., 2016). Our mutagenesis experiments show that an 302 inner pore residue (K799) that is unique to Nav1.9 determines the inability of Nav $\beta 4$ peptide to induce

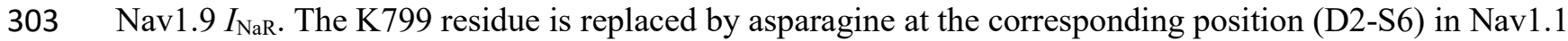

$304-$ Nav1.8. The homology model of Nav1.9 shows that the side chain of K799 projects into the channel 305 pore (Lin et al., 2016), and thus the positively charged residue may prevent the positively charged Nav $\beta 4$ 306 peptide from accessing its binding site in the Nav1.9 inner pore by electrostatic repulsion, which is 307 consistent with previous findings that positive residues are crucial for Nav $\beta 4$ peptide mediating $I_{\mathrm{NaR}}$ 308 (Lewis and Raman, 2011). 
The most salient finding from this study is identification of A-type FHFs as novel $I_{\text {NaR }}$ mediators of Nav1.8 and Nav1.9 and, to a lesser extent, Nav1.5 and Nav1.7. A-type FHFs consist of a long Nterminus, an FGF-like $\beta$-trefoil core and a short C-terminus (Goldfarb, 2005) (Fig. 6a). Here we show that

312 the long N-terminus of A-type FHFs, specifically residues 2-21, is the molecular component responsible

313 for inducing TTX-resistant $I_{\mathrm{NaR}}$. While the F2A and F4A peptides show limited sequence similarity to the 314 Nav $\beta 4$ peptide, they all exhibit similar patterns of interactions with VGSCs. The F2A, F4A and Nav $\beta 4$ 315 peptides can all accelerate fast inactivation (likely through open-channel block), can be quickly expelled 316 from the channel pore upon repolarization, and have positive and hydrophobic residues that seems to be 317 essential for inducing $I_{\mathrm{NaR}}$ (Dover et al., 2010; Lewis and Raman, 2010; Venkatesan et al., 2014). These 318 similarities lead us to propose that A-type FHFs induce $I_{\mathrm{NaR}}$ via the N-terminus by a relief-of-open319 channel-block mechanism, similar to mechanism proposed for the Nav $\beta 4$ peptide-dependent $I_{\text {NaR }}$ (Lewis and Raman, 2014).

321 Previous studies proposed that FHF4 isoforms may regulate Nav1.6 $I_{\text {NaR }}$ generation in Purkinje neurons

322 (Yan et al., 2014; White et al., 2019). Although initially it was suggested that FHF4B indirectly enhanced $323 I_{\mathrm{NaR}}$ by attenuating inactivation of Nav1.6 (Yan et al., 2014), a more recent study indicated that FHF4A 324 directly mediated Nav1.6 $I_{\mathrm{NaR}}$, showing a short peptide derived from a region of FHF4A adjacent to the $\beta$ 325 trefoil core (residues 51-63) was able to induce robust $I_{\mathrm{NaR}}$ in FHF4A knockout mice (White et. Al, 2019). 326 However, our data do not support the idea that FHF4A serves as a direct mediator of Nav1.6 $I_{\mathrm{NaR}}$, because 327 FHF4A failed to mediate Nav1.6 $I_{\mathrm{NaR}}$ in our heterologous expression systems. Previously we demonstrated that FHF2A decreases Nav1.6 $I_{\mathrm{NaR}}$ in DRG neurons. In contrast, FHF2B, indirectly enhances $I_{\mathrm{NaR}}$ generation in DRG neurons (Barbosa et al., 2017). FHF2B lacks the long N-terminus of Atype FHFs but retains the $\beta$-trefoil core found in all FHFs that can bind to the cytoplasmic tail of VGSCs

331 and destabilizes Nav1.6 fast-inactivation (also see Fig. 9h). Interestingly, FHF4 knockout accelerates the 332 onset of fast inactivation of sodium currents (White et al., 2019) and hyperpolarizes the voltage333 dependence of sodium current inactivation (Bosch et al., 2015) in cerebellar Purkinje neurons. This 
makes it possible that FHF4 isoforms regulate Nav1.6 $I_{\mathrm{NaR}}$ in neurons, at least in part, by reducing channel fast inactivation, instead of direct mediating $I_{\mathrm{NaR}}$. Computational modeling of $I_{\mathrm{NaR}}$ generation in mouse cerebellar Purkinje neurons suggests that blocking particle-independent mechanisms may account for TTX-sensitive $I_{\mathrm{NaR}}$ in some neuronal populations (Ransdell et al., 2022). heterologous expression systems, our data show that FHF4A can induce long-term inactivation of Nav1.6 in ND7/23 cells (Fig. 10), which is consistent with previous studies demonstrating that A-type FHFs

341 induce long-term inactivation of Nav1.6 and Nav1.5 (Dover et al., 2010; Yan et al., 2014; Yang et al., 342 2016; Barbosa et al., 2017). One possible explanation for the induction of long-term inactivation versus

343 the induction of $I_{\mathrm{NaR}}$ generation is that A-type FHF N-terminus may bind more strongly to Nav1.6 and 344 some other VGSCs than to Nav1.8 and Nav1.9. During repolarization, the driving force is only powerful 345 enough to repel and unbind A-type FHF N-terminus from Nav1.8 and Nav1.9, but not from Nav1.6, and 346 thus induces robust $I_{\mathrm{NaR}}$ from Nav1.8 and Nav1.9, but long-term inactivation in Nav1.6. However, we 347 cannot rule out the possibility that post-translational modifications of either Nav1.6 or FHF4A allows 348 FHF4A to directly induce $I_{\mathrm{NaR}}$ in Nav1.6, rather than inducing long-term inactivation, in specific neuronal populations such as cerebellar Purkinje neurons.

Intriguingly, our data show that heterologous expression of A-type FHF is sufficient to induce $I_{\mathrm{NaR}}$ in not 351 only Nav1.8 and Nav1.9, but also, at least to some extent, in Nav1.5 and Nav1.7. This opens the door to 352 further investigation of the molecular mechanism and the molecular manipulation of $I_{\mathrm{NaR}}$. Our data show 353 that F4A peptide at up to $1 \mathrm{mM}$, a non-physiological concentration, is required to fully induce the same 354 level of $I_{\mathrm{NaR}}$ as those induced by full-length FHF4A. This concentration is fivefold to tenfold higher than that of Nav $\beta 4$ peptide $(100-200 \mu \mathrm{M})$ that is required to reconstitute TTX-sensitive $I_{\mathrm{NaR}}$. The unusually high concentration apparently is due to the lack of the FHF $\beta$-trefoil core. The $\beta$-trefoil core does not directly generate $I_{\mathrm{NaR}}$, but it is likely crucial to facilitating $I_{\mathrm{NaR}}$ generation induced by $\mathrm{N}$-terminus residues in A-type FHFs, as the core binding to the cytoplasmic tail of VGSCs (Liu et al., 2001; Goetz et al., 2009) 
would greatly raise the local concentration of the N-terminus near the channel pore. In addition, our data and that of others demonstrate that the $\beta$-trefoil domain shifts the voltage-dependence of steady-state

361 inactivation in the positive direction, augmenting the "window currents" region (see Fig. 1b, $d$ ), where

362 VGSCs activate but do not fully inactivate. Lewis and Raman (2013) showed that open-channel blockers

363 might have higher affinity in VGSCs with DIVS4 deployed than with DIVS4 in the resting or partially

364 deployed configuration. This also suggests that the molecular manipulation of $I_{\mathrm{NaR}}$ might be achieved by

365 inhibiting the interaction of A-type FHF $\beta$-trefoil core with VGSC C-terminus.

Overall, our work substantially increases understanding of the role of A-type FHFs in sensory neuron excitability. We show that A-type FHFs exert various impact on neuronal excitability by differentially modulating the activities of VGSC isoforms. The accumulation of long-term inactivation seems to be the predominant effect of A-type FHFs on TTX-sensitive VGSC isoforms, although FHF-mediated $I_{\text {NaR }}$ (only $0.3 \%$ of transient peak current) are inducible with some TTX-sensitive isoforms (Fig. $9 c, f$ ). By promoting

371 long-term inactivation, FHF2A accumulatively decreases TTX-sensitive sodium currents (e.g. Nav1.6,

372 Nav1.7) by $>20 \%$ (Venkatesan et al., 2014; Effraim et al., 2019). Prior studies demonstrated that A-type

373 FHFs reduced action potential firing in hippocampal neurons, cerebellar granule neurons (Dover et al.,

374 2010; Venkatesan et al., 2014) and in medium-sized DRG neurons, where Nav1.6 channels are

375 predominantly expressed (Barbosa et al., 2017). Nav1.8 and Nav1.9 are two TTX-resistant subtypes

376 mainly expressed in nociceptive sensory neurons (Fang et al., 2002; Cummins et al., 2007). In Fig. 6, we

377 demonstrate that A-type FHF-mediated $I_{\text {NaR }}$ significantly upregulate excitability of nociceptive DRG

378 neurons. The $I_{\mathrm{NaR}}$ also result in broader action potentials and higher firing frequency. These observations

379 are similar to those detected in Nav1.8 T790A-transfected DRG neurons, in which the T790A variant

380 identified in the Possum transgenic mouse strain leads to increased $I_{\mathrm{NaR}}$ and enhanced excitability (Xiao et

381 al., 2019). In addition to DRG neurons, Nav1.8/Nav1.9 have been colocalized with A-type FHFs within

382 other neuronal populations, such as trigeminal ganglion neurons, myenteric neurons, magnocellular

383 neurosecretory cells of the supraoptic nucleus, the outer layers of the substantia gelatinosa, and cerebellar 
neurons in animal models of multiple sclerosis (Craner et al., 2003; Vohra et al., 2006; Heanue et al., 2006; Huang et al., 2014; Osorio et al., 2014). This opens up the possibility that A-type FHF-mediated $I_{\mathrm{NaR}}$ extensively regulate excitability of the neurons throughout the PNS and CNS.

Materials and Methods

Plasmids, Sodium channel constructs and mutagenesis. Human FHF2A and FHF2B sequences were subcloned into pmTurquoise2-N1 vector as described by Barbosa et al. (2017). The pCMV6-AC-GFP plasmid encoding human FHF1A, FHF3A or FHF4A was purchased from Origene USA Technologies, Inc. (Rockville, MD). The cDNA construct encoding the human Nav1.5, mouse Nav1.8 and human Nav1.8 were subcloned into a pcDNA3.1 expression vector, respectively. The mutation N927K in Nav1.5 was constructed using the QuikChange XL (Stratagene) mutagenesis kit following the manufacturer's instructions (Stratagene). Mutations were confirmed by sequencing. The scrambled shRNA and FHF4shRNA constructs were generously provided by Dr. Geoffrey S Pitt (Duke University). The scrambled shRNA and FHF4shRNA were subcloned into pAdTrack and pLVTHM vectors, respectively.

Cell culture and transfection. Rat DRG neurons were acutely dissociated and cultured according to the procedure described previously (Xiao et al., 2019). Briefly, young adult (8 weeks) Sprague Dawley rats of either sex, in adherence with animal procedures approved by the Indiana University School of Medicine Institutional Animal Care and Use Committee, were killed by decapitation without anesthetization. All DRGs were removed quickly from the spinal cord and then incubated in DMEM containing collagenase

$403(1 \mathrm{mg} / \mathrm{ml})$ and protease $(1 \mathrm{mg} / \mathrm{ml})$. After the ganglia were triturated in DMEM supplemented with $10 \%$ 404 FBS, cells were seeded on glass coverslips coated with poly-D-lysine and laminin. Cultures were 405 maintained at $37^{\circ} \mathrm{C}$ in a $5 \% \mathrm{CO} 2$ incubator. In order to be consistent with our previous studies (19), the 406 Helios Gene Gun (Bio-Rad Laboratories) was used to transiently cotransfect rat DRG neurons. Cells were 407 cotransfected with an internal ribosome entry site-EGFP (IRES-EGFP) vector plasmid (or an IRES- 
DsRed vector plasmid) containing a Nav1.8 shRNA targeting the rat Nav1.8 but not the codon optimized mouse Nav1.8 sequences. After transfection, DRG neurons were incubated in 10\% FBS DMEM medium

410 supplemented with mitotic inhibitors, 5-fluoro-2-deoxyuridine (50 $\mu \mathrm{M}$, Sigma Aldrich) and uridine (150

$411 \mu \mathrm{M}$, Sigma Aldrich), to prevent overgrowth of the supporting cells. DRG recordings were obtained from

412 cells 2-5 days after transfection. Transfected cells were selected for recordings based on their ability to

413 express EGFP. Under control conditions, the endogenous Nav1.8-type currents have an average current

414 density of $947 \pm 72 \mathrm{pA} / \mathrm{pF}(\mathrm{n}=70)$ and the Nav1.8 shRNA reduces endogenous Nav1.8-type current

415 amplitudes in DRG neurons by 98\% (Xiao et al., 2019).

Human Nav1.9, Nav1.9 K799N, Nav1.7 and Nav1.7 N945K channel cDNAs were stably expressed in the

417 HEK-293- $\beta 1 / \beta 2$ cell lines as described previously (Lin et al., 2016) and provided by Icagen Inc (Durham,

418 North Carolina). They were incubated in 10\% DMEM medium supplemented with G418 (400 mg/L) and

419 puromycin $(0.5 \mathrm{mg} / \mathrm{L})$. Cell lines were transiently transfected by FHF1A, FHF2A, FHF2B, FHF3A or

420 FHF4A using the Invitrogen Lipofectamine 2000. Nav1.9 cells were seeded on glass coverslips and

421 incubated at $30{ }^{\circ} \mathrm{C} 24 \mathrm{hrs}$ prior to patch-clamp recording.

422 HEK293 cells and ND7/23 cells were grown under standard tissue culture conditions $\left(5 \% \mathrm{CO} 2\right.$ and $\left.37{ }^{\circ} \mathrm{C}\right)$

423 in Dulbecco's modified Eagle's medium supplemented with 10\% fetal bovine serum. Using the Invitrogen

424 Lipofectamine 2000, human Nav1.5 and the mutant construct (N927K) were transiently co-transfected

425 with FHF2B, FHF2A or FHF4A into HEK293 cells. The construct human Nav1.8 was transiently

426 transfected into ND7/23 cells. The lipofectamine-DNA mixture was added to the cell culture medium and

427 left for $3 \mathrm{~h}$ after which the cells were washed with fresh medium. Cells with green fluorescent protein

428 fluorescence were selected for whole-cell patch clamp recordings 36-72 $\mathrm{h}$ after transfection.

429 Electrophysiological recordings. Whole-cell voltage-clamp recordings were performed at room

430 temperature $\left(\sim 21^{\circ} \mathrm{C}\right)$ using an EPC-10 amplifier and the Pulse program (HEKA Electronics). Recordings 
431 for hNav1.7 and hNav1.7 N945K were conducted at Icagen, Inc under similar conditions but with an

432 Axopatch 200B amplifier and PCLAMP software (Molecular Devices).

433 For voltage clamp recordings, fire-polished electrodes (1.0 - 2.0 M $)$ ) were fabricated from $1.7 \mathrm{~mm}$

434 capillary glass using a P-97 puller (Sutter Instruments), and the tips were coated with sticky wax

435 (KerrLab) to minimize capacitive artifacts and increase series resistance compensation. The pipette

436 solution contained (in $\mathrm{mM}$ ): $140 \mathrm{CsF}, 1.1 \mathrm{EGTA}, 10 \mathrm{NaCl}$ and $10 \mathrm{HEPES}, \mathrm{pH}$ 7.3. The bathing solution

437 was (in mM): $130 \mathrm{mM} \mathrm{NaCl}, 30 \mathrm{mM}$ TEA Chloride, $1 \mathrm{mM} \mathrm{MgCl}_{2}, 3 \mathrm{mM} \mathrm{KCl}, 1 \mathrm{mM} \mathrm{CaCl} 2,0.05 \mathrm{mM}$

$438 \mathrm{CdCl}_{2}, 10 \mathrm{mM}$ HEPES, and $10 \mathrm{mM}$ D-glucose, $\mathrm{pH} 7.3$ (adjusted with $\mathrm{NaOH}$ ). Tetrodotoxin (TTX; 500

$439 \mathrm{nM}$ ) was added to the bath solution in order to block endogenous TTX-sensitive currents in DRG neurons,

$440 \quad$ Nav1.9 and K799N stable cells, and cells expressing Nav1.8, Nav1.5 and the mutant N927K. The liquid

441 junction potential for these solutions was $<8 \mathrm{mV}$; data were not corrected to account for this offset. The

442 offset potential was zeroed before contacting the cell. After establishing the whole-cell recording

443 configuration, the resting potential was held at $-120 \mathrm{mV}$ or $-100 \mathrm{mV}$ for $5 \mathrm{~min}$ to allow adequate

444 equilibration between the micropipette solution and the cell interior. Linear leak subtraction, based on

445 resistance estimates from four to five hyperpolarizing pulses applied before the depolarizing test potential,

446 was used for all voltage clamp recordings. Membrane currents were usually filtered at $5 \mathrm{kHz}$ and sampled

447 at $20 \mathrm{kHz}$. Voltage errors were minimized using 70\% - 90\% series resistance compensation, and the

448 capacitance artifact was canceled using the computer-controlled circuitry of the patch clamp amplifier.

449 Steady-State activation: Families of sodium currents were induced by 50 -ms depolarizing steps to various

450 potentials ranging from -120 to $+40 \mathrm{mV}$ in $5-\mathrm{mV}$ (or $10-\mathrm{mV}$ ) increments. The conductance was

451 calculated using the equation $\mathrm{G}(\mathrm{Nav})=\mathrm{I} /(\mathrm{V}-\mathrm{Vrev})$ in which $\mathrm{I}, \mathrm{V}$, and Vrev represent inward current

452 value, membrane potential, and reversal potential, respectively.

453 Steady-state inactivation: The voltage dependence of steady-state inactivation was estimated using a

454 standard double pulse protocol in which sodium currents were induced by a 50-ms depolarizing potential 
of $0 \mathrm{mV}$ following a $500-\mathrm{ms}$ prepulse at potentials that ranged from -130 to $+10 \mathrm{mV}$ with a $10-\mathrm{mV}$ increment. Currents were plotted as a fraction of the maximum peak current. To obtain the midpoint

457 voltages $\left(\mathrm{V}_{1 / 2}\right)$ and slope factor $(\mathrm{k})$, the curves of both steady-state activation and inactivation were fitted 458 to a Boltzmann function.

Recovery from inactivation: Recovery from inactivation was assayed by the protocol that the cells were prepulsed to $0 \mathrm{mV}$ for $50 \mathrm{~ms}$ to inactivate sodium channels and then brought back to $-100 \mathrm{mV}$ for increasing recovery durations before the test pulse to $0 \mathrm{mV}$.

Resurgent currents: $I_{\mathrm{NaR}}$ were elicited by repolarizing voltage steps from $+10 \mathrm{mV}$ to -100 for $100 \mathrm{~ms}$ (200 ms, or $1000 \mathrm{~ms}$ as indicated in Figures (inset)) in $-5 \mathrm{mV}$ increments, following a 20-ms depolarizing potential of $+30 \mathrm{mV}$ (or $+100 \mathrm{mV}$ ). To avoid contamination from tail currents, Nav $\beta 4$-induced Nav1.5 $I_{\mathrm{NaR}}$ were measured after $3.0 \mathrm{~ms}$ into the repolarization pulse, FHF-induced resurgent currents in Nav1.5, Nav1.7 and Nav1.9 were measured after $4.0 \mathrm{~ms}$ into the repolarization pulse, and FHF-induced Nav1.8

$467 I_{\mathrm{NaR}}$ were measured after $20 \mathrm{~ms}$ into the repolarization pulse. The relative $I_{\mathrm{NaR}}$ in Nav1.5, Nav1.7 and 468 Nav1.8 were calculated by normalizing to the peak transient current elicited at $0 \mathrm{mV}$, but the relative of 469 Nav1.9 resurgent currents were by normalizing to the peak transient current at $-30 \mathrm{mV}$.

470 For current-clamp recordings, fire-polished electrodes $(4.0-5.0 \mathrm{M} \Omega)$ were fabricated from $1.2 \mathrm{~mm}$ 471 capillary glass using a P-97 (Sutter Instruments). The pipette solution contained the following (in $\mathrm{mM}$ ):

$472140 \mathrm{KCl}, 5 \mathrm{MgCl}_{2}, 5$ EGTA, $2.5 \mathrm{CaCl}_{2}, 4 \mathrm{ATP}, 0.3 \mathrm{GTP}$, and $10 \mathrm{HEPES}$, pH 7.3 (adjusted with $\mathrm{KOH}$ ).

473 The bathing solution contained the following (inmM): $140 \mathrm{NaCl}, 1 \mathrm{MgCl} 2,5 \mathrm{KCl}, 2 \mathrm{CaCl}_{2}, 10 \mathrm{HEPES}$, 474 and 10 glucose, $\mathrm{pH} 7.3$ (adjusted with $\mathrm{NaOH}$ ). Neurons were allowed to stabilize for 3 min in the current475 clamp mode before initiating current injections to measure action potential activity.

476 Immunocytochemistry. Immunocytochemistry was performed according the procedure as described 477 previously (17). Briefly, the Helios Gene Gun (Bio-Rad Laboratories) was used to transiently transfect the 478 scrambled shRNA, or FHF4shRNA in cultured DRG neurons. Three days after transfection, DRG 
neurons were fixed with 4\% PFA (0.1 M phosphate buffer, $\mathrm{pH} 7.4)$ for 20 min and washed in PBS. Cells were then permeabilized in $1 \%$ Triton X-100 in PBS for 20 min at room temperature $\left(\sim 21{ }^{\circ} \mathrm{C}\right)$, washed in

481 PBS, blocked for $2 \mathrm{~h}(10 \%$ normal goat serum, 0.1\% Triton X-100 in PBS) at room temperature, and

482 washed with PBS. Cells were then incubated with monoclonal FHF4 antibody (1:200, N56/21, UC

483 Davis/NIH NeuroMab Facility) or polyclonal anti-Navß4 antibody (1:500, \#Ab80539, Abcam) diluted in

484 blocking solution over night at $4{ }^{\circ} \mathrm{C}$. After additional PBS washes, cells were incubated with secondary antibody AlexaFluorTM Plus 555 Goat Anti-Mouse IgG (Invitrogen) in blocking solution at 1:1000 concentration for $2 \mathrm{~h}$ at room temperature. Coverslips were mounted in Prolong Gold Antifade

487 (Invitrogen) and DRG neurons imaged using Leica Microscope system with a 20 objective (Biocompare). Images were analyzed with Leica software, and corrected mean cell fluorescence was calculated in Excel (Microsoft) by applying measurements obtained from image analysis using the equations: $\mathrm{CMCF}=($ mean fluorescence intensity of selected cell) - (mean fluorescence of background).

Experimental design and statistical analysis. The acquisition of control and experimental data was

492 randomized. Data were analyzed using the software programs PulseFit (HEKA) and GraphPad Prism 5.0

493 (GraphPad Software, Inc., San Diego, CA). All data are shown as mean \pm S.E. The number of separate experimental cells is presented as $n$. Statistical analysis was performed by Student's t test, one-way ANOVA and $\chi^{2}$ analysis, and $\mathrm{p}<0.05$ indicated a significant difference.

\section{Acknowledgment}

498 This work was supported, in whole or in part, by the National Institute of Neurological Disorders and 499 Stroke of the National Institutes of Health under Award Numbers R21NS109896 (to Y. X. and T. R. C) 500 and NS053422 (to T. R. C.), and the Indiana Spinal Cord \& Brain Injury Research Fund from the Indiana

501 State Department of Health (2020) (to Y. X.). We thank Dr. Geoffrey S. Pitt for generously providing the scrambled shRNA and FHF4shRNA constructs. 
bioRxiv preprint doi: https://doi.org/10.1101/2022.03.04 482974 this version posted March 5, 2022. The copyright holder for this preprint (which was not certified by peer review) is the author/funder, who has granted bioRxiv a license to display the preprint in perpetuity. It is made available under aCC-BY 4.0 International license.

\section{Author Contributions}

504 J.W.T and Y.P. performed experiments, analyzed data, and contributed to writing the manuscript, A.Z.

505 and Z.L. performed experiments and analyzed data. Y.X. and T.R.C. conceived the study, oversaw the

506 study, designed experiments and wrote the manuscript. Y.X. also performed experiments and analyzed

507 data.

\section{Competing Interests statement}

509 No authors declare no conflicts of interest. 


\section{References}

512 Afshari FS, Ptak K, Khaliq ZM, Grieco TM, Slater NT, McCrimmon DR, Raman IM. 2004. Resurgent

513 Na currents in four classes of neurons of the cerebellum. J. Neurophysiol., 92:2831-2843.

514 Aman TK, Grieco-Calub TM, Chen C, Rusconi R, Slat EA, Isom LL, Raman IM. 2009. Regulation of 515 persistent Na current by interactions between beta subunits of voltage-gated Na channels. J. Neurosci., 29:2027-42.

Attwell D, Cohen I, Eisner D, Ohba M, Ojeda C. 1979. The steady state TTX-sensitive (“window") sodium current in cardiac Purkinje fibres. Pflugers Arch, 379:137-142.

Bant JS, Raman IM. 2010. Control of transient, resurgent, and persistent current by open-channel block

Bant JS, Aman TK, Raman IM. 2013. Antagonism of lidocaine inhibition by open-channel blockers that generate resurgent Na current. J. Neurosci., 33:4976-87.

Barbosa C, Tan ZY, Wang R, Xie W, Strong JA, Patel RR, Vasko MR, Zhang JM, Cummins TR. 2015. Nav $\beta 4$ regulates fast resurgent sodium currents and excitability in sensory neurons. Mol. Pain, 11:60. differentially regulate Nav1.6-mediated resurgent sodium currents in dorsal root ganglion neurons. Pflugers Arch., 469:195-212. sodium channel SNS is abnormally expressed in the brains of mice with experimental allergic encephalomyelitis and humans with multiple sclerosis. Proc. Natl. Acad. Sci. U S A, 97:11598-602. 
531 Bosch MK, Carrasquillo Y, Ransdell JL, Kanakamedala A, Ornitz DM, Nerbonne JM. 2015. Intracellular FGF14 (iFGF14) Is Required for Spontaneous and Evoked Firing in Cerebellar Purkinje Neurons and for Motor Coordination and Balance. J Neurosci., 35:6752-6769. channelopathies. J. Clin. Invest.,120:80-3. 57:397-409.

Chen Y, Yu FH, Sharp EM, Beacham D, Scheuer T, Catterall WA. 2008. Functional properties and differential neuromodulation of $\mathrm{Na}(\mathrm{v}) 1.6$ channels. Mol. Cell. Neurosci., 38:607-15.

541 Cox JJ, Reimann F, Nicholas AK, Thornton G, Roberts E, Springell K, Karbani G, Jafri H, Mannan J, 542 Raashid Y, Al-Gazali L, Hamamy H, Valente EM, Gorman S, Williams R, McHale DP, Wood JN, 543 Gribble FM, Woods CG. 2006. An SCN9A channelopathy causes congenital inability to experience $544 \quad$ pain. Nature, $444: 894-8$.

545 Craner MJ, Kataoka Y, Lo AC, Black JA, Baker D, Waxman SG. 2003. Temporal course of upregulation 546 of $\mathrm{Na}(\mathrm{v}) 1.8$ in Purkinje neurons parallels the progression of clinical deficit in experimental allergic 547 encephalomyelitis. J. Neuropathol. Exp. Neurol., 62:968-975.

548 Cummins TR, Dib-Hajj SD, Waxman SG. 2004. Electrophysiological properties of mutant Nav1.7 549 sodium channels in a painful inherited neuropathy. J. Neurosci., 24:8232-8236.

550 Cummins TR, Sheets PL, Waxman SG. 2007. The roles of sodium channels in nociception: Implications 551 for mechanisms of pain. Pain, 131:243-57. 
552

553

554

555

556

557

558

559

560

561

562

563

564

565

566

567

568

569

570

571

572

Dib-Hajj SD, Cummins TR, Black JA, Waxman SG. 2010. Sodium channels in normal and pathological pain. Annual Review of Neuroscience, 33:325-347.

Dib-Hajj SD, Black JA, Waxman SG. 2015. NaV1.9: a sodium channel linked to human pain. Nat. Rev. Neurosci., 16:511-9.

Dover K, Solinas S, D'Angelo E, Goldfarb M. 2010. Long-term inactivation particle for voltage-gated sodium channels. J. Physiol., 588:3695-711.

Effraim PR, Huang J, Lampert A, Stamboulian S, Zhao P, Black JA, Dib-Hajj SD, Waxman SG. 2019. Fibroblast growth factor homologous factor 2 (FGF-13) associates with Nav1.7 in DRG neurons and alters its current properties in an isoform-dependent manner. Neurobiol Pain, 6:100029.

Enomoto A, Han JM, Hsiao CF, Wu N, Chandler SH. 2006.Participation of sodium currents in burst generation and control of membrane excitability in mesencephalic trigeminal neurons. J. Neurosci., 26:3412-3422.

Fang X, Djouhri L, Black JA, Dib-Hajj SD, Waxman SG, Lawson SN. 2002. The presence and role of the tetrodotoxin-resistant sodium channel $\mathrm{Na}(\mathrm{v}) 1.9(\mathrm{NaN})$ in nociceptive primary afferent neurons. $J$ Neurosci, 22:7425-7433.

Goetz R, Dover K, Laezza F, Shtraizent N, Huang X, Tchetchik D, Eliseenkova AV, Xu CF, Neubert TA, Ornitz DM, Goldfarb M, Mohammadi M. 2009. Crystal structure of a fibroblast growth factor homologous factor (FHF) defines a conserved surface on FHFs for binding and modulation of voltagegated sodium channels. J. Biol. Chem., 284:17883-96.

Goldfarb M. 2005. Fibroblast growth factor homologous factors: evolution, structure, and function. Cytokine Growth Factor Rev., 16:215-20. 
573 Grieco TM, Raman IM. 2004. Production of resurgent current in NaV1.6-null Purkinje neurons by

574 slowing sodium channel inactivation with beta-pompilidotoxin. J Neurosci. 24:35-42.

575 Grieco TM, Malhotra JD, Chen C, Isom LL, Raman IM. 2005. Open-channel block by the cytoplasmic

576 tail of sodium channel beta4 as a mechanism for resurgent sodium current. Neuron, 45: 233-44.

577 Heanue TA, Pachnis V. 2006. Expression profiling the developing mammalian enteric nervous system

578 identifies marker and candidate Hirschsprung disease genes. Proc. Natl. Acad. Sci. U S A, 103:6919-24.

579 Huang J, Yang Y, Zhao P, Gerrits MM, Hoeijmakers JG, Bekelaar K, Merkies IS, Faber CG, Dib-Hajj SD,

580 Waxman SG. 2013. Small-fiber neuropathy Nav1.8 mutation shifts activation to hyperpolarized

581 potentials and increases excitability of dorsal root ganglion neurons. J. Neurosci., 33:14087-97.

582 Huang J, Han C, Estacion M, Vasylyev D, Hoeijmakers JG, Gerrits MM, Tyrrell L, Lauria G, Faber CG,

583 Dib-Hajj SD, Merkies IS, Waxman SG, PROPANE Study Group. 2014. Gain-of-function mutations in

584 sodium channel $\mathrm{Na}(\mathrm{v}) 1.9$ in painful neuropathy. Brain, 137:1627-42.

585 Jarecki BW, Piekarz AD, Jackson JO, Cummins TR. 2010. Human voltage-gated sodium channel

586 mutations that cause inherited neuronal and muscle channelopathies increase resurgent sodium

587 currents. J Clin Invest, 120:369-78.

588 Kim JH, Kushmerick C, von Gersdorff H. 2010. Presynaptic resurgent Na+ currents sculpt the action

589 potential waveform and increase firing reliability at a CNS nerve terminal. $J$. Neurosci., 30:15479-

$590 \quad 15490$.

591 Lewis AH, Raman IM. 2011. Cross-species conservation of open-channel block by Na channel $\beta 4$

592 peptides reveals structural features required for resurgent Na current. J. Neurosci., 31:11527-36. 
Lewis AH, Raman IM. 2013. Interactions among DIV voltage-sensor movement, fast inactivation, and resurgent $\mathrm{Na}$ current induced by the NaV4 open-channel blocking peptide. J. Gen. Physiol., 142:191206. 38.

Li GD, Wo Y, Zhong MF, Zhang FX, Bao L, Lu YJ, Huang YD, Xiao HS, Zhang X. 2002. Expression of fibroblast growth factors in rat dorsal root ganglion neurons and regulation after peripheral nerve injury. Neuroreport, 13:1903-7.

Lin Z, Santos S, Padilla K, Printzenhoff D, Castle NA. 2016. Biophysical and Pharmacological Characterization of Nav1.9 Voltage Dependent Sodium Channels Stably Expressed in HEK-293 Cells. PLoS One, 11:e0161450.

Liu CJ, Dib-Hajj SD, Waxman SG. 2001. Fibroblast growth factor homologous factor 1B binds to the C terminus of the tetrodotoxin-resistant sodium channel rNav1.9a (NaN). J. Biol. Chem., 276:18925-33. 2005. Fibroblast growth factor 14 is an intracellular modulator of voltage-gated sodium channels. $J$. Physiol., 569:179-93. subunit in unmyelinated fibres and its role in the striatum. Nat Commun. 21;5:5525. sodium channel $\beta$ subunits. Open Biol., 5:140-192. 
615

616

617

618

619

620

621

622

623

624

625

626

627

628

629

630

631

632

633

634

635

Osorio N, Korogod S, Delmas P. 2014. Specialized functions of Nav1.5 and Nav1.9 channels in electrogenesis of myenteric neurons in intact mouse ganglia. J. Neurosci., 34:5233-44.

Pan Y, Cummins TR. 2020. Distinct functional alterations in SCN8A epilepsy mutant channels. J Physiol. 598:381-401. Patel RR, Barbosa C, Brustovetsky T, Brustovetsky N, Cummins TR. 2016 Aberrant epilepsy-associated mutant Nav1.6 sodium channel activity can be targeted with cannabidiol. Brain, 139:2164-81.

Raman IM, Bean BP. 1997. Resurgent sodium current and action potential formation in dissociated cerebellar Purkinje neurons. J. Neurosci., 17:4517-4526.

Ransdell JL, Dranoff E, Lau B, Lo WL, Donermeyer DL, Allen PM, Nerbonne JM. 2017. Loss of Navß4Mediated Regulation of Sodium Currents in Adult Purkinje Neurons Disrupts Firing and Impairs Motor Coordination and Balance. Cell Rep., 20:1502.

Ransdell JL, Moreno JD, Bhagavan D, Silva JR, Nerbonne JM. 2022. Intrinsic mechanisms in the gating of resurgent $\mathrm{Na}^{+}$currents. Elife 11:e70173.

Rush AM, Wittmack EK, Tyrrell L, Black JA, Dib-Hajj SD, Waxman SG. 2006. Differential modulation of sodium channel $\mathrm{Na}(\mathrm{v}) 1.6$ by two members of the fibroblast growth factor homologous factor 2 subfamily. Eur J Neurosci., 23:2551-2562.

Tanaka BS, Zhao P, Dib-Hajj FB, Morisset V, Tate S, Waxman SG, Dib-Hajj SD. 2016. A gain-offunction mutation in Nav1.6 in a case of trigeminal neuralgia. Mol. Med., 22.

Theile JW, Jarecki BW, Piekarz AD, Cummins TR. 2011. Nav1.7 mutations associated with paroxysmal extreme pain disorder, but not erythromelalgia, enhance Navbeta4 peptide-mediated resurgent sodium currents. J. Physiol., 589:597-608. 
Venkatesan K, Liu Y, Goldfarb M. 2014. Fast-onset long-term open-state block of sodium channels by Atype FHFs mediates classical spike accommodation in hippocampal pyramidal neurons. J. Neurosci., 34:16126-39.

Vohra BP, Tsuji K, Nagashimada M, Uesaka T, Wind D, Fu M, Armon J, Enomoto H, Heuckeroth RO. 2006. Differential gene expression and functional analysis implicate novel mechanisms in enteric nervous system precursor migration and neuritogenesis. Dev Biol, 298:259-71.

White HV, Brown ST, Bozza TC, Raman IM. 2019. Effects of FGF14 and Na(V)ß4 deletion on transient and resurgent Na current in cerebellar Purkinje neurons. J. Gen. Physiol., 151:1300-1318.

Wildburger NC, Ali SR, Hsu WC, Shavkunov AS, Nenov MN, Lichti CF, LeDuc RD, Mostovenko E, Panova-Elektronova NI, Emmett MR, Nilsson CL, Laezza F. 2015. Quantitative proteomics reveals protein-protein interactions with fibroblast growth factor 12 as a component of the voltage-gated sodium channel 1.2 (nav1.2) macromolecular complex in Mammalian brain. Mol. Cell Proteomics, 14:1288-300.

Wittmack EK, Rush AM, Craner MJ, Goldfarb M, Waxman SG, Dib-Hajj SD. 2004. Fibroblast growth factor homologous factor 2B: association with Nav1.6 and selective colocalization at nodes of Ranvier of dorsal root axons. J. Neurosci., 24:6765-75.

Wang C, Hennessey JA, Kirkton RD, Wang C, Graham V, Puranam RS, Rosenberg PB, Bursac N, Pitt GS. 2011a. Fibroblast growth factor homologous factor 13 regulates $\mathrm{Na}+$ channels and conduction velocity in murine hearts. Circ. Res., 109:775-82.

Wang C, Wang C, Hoch EG, Pitt GS. 2011b. Identification of novel interaction sites that determine specificity between fibroblast growth factor homologous factors and voltage-gated sodium channels. $J$. Biol. Chem., 286:24253-63. 
658 Xiao Y, Barbosa C, Pei Z, Xie W, Strong JA, Zhang JM, Cummins TR. 2019. Increased Resurgent

659 Sodium Currents in Nav1.8 Contribute to Nociceptive Sensory Neuron Hyperexcitability Associated

660 with Peripheral Neuropathies. J. Neurosci., 39:1539-1550.

661 Xie W, Tan ZY, Barbosa C, Strong JA, Cummins TR, Zhang JM. 2016. Upregulation of the sodium

662 channel NaVbeta4 subunit and its contributions to mechanical hypersensitivity and neuronal

663 hyperexcitability in a rat model of radicular pain induced by local dorsal root ganglion inflammation.

$664 \quad$ Pain, 157:879-891.

665 Yan H, Pablo JL, Wang C, Pitt GS. 2014. FGF14 modulates resurgent sodium current in mouse cerebellar 666 Purkinje neurons. Elife, 3, e04193.

667 Yang J, Wang Z, Sinden DS, Wang X, Shan B, Yu X, Zhang H, Pitt GS, Wang C. 2016. FGF13

668 modulates the gating properties of the cardiac sodium channel $\mathrm{Na}(\mathrm{v}) 1.5$ in an isoform-specific manner.

669 Channels (Austin), 10:410-420.

670

671 
674 systems. (a) Family of classical currents recorded from ND7/23 cells expressing recombinant Nav1.8.

675 Currents were elicited by 50 -ms depolarizing voltage steps from $+25 \mathrm{mV}$ to $-55 \mathrm{mV}$ in $-10 \mathrm{mV}$

676 increments from a holding potential of $-100 \mathrm{mV}$ (inset). (b) Effects of FHF2B, FHF2A and FHF4A on

677 steady-state activation $(\mathrm{p}<0.0001,0.0035,0.0077 v s$ control, respectively) and inactivation $(\mathrm{p}=0.0002$,

$678<0.0001,<0.0001$ vs control, respectively) of Nav1.8. (c) FHF2B, FHF2A and FHF4A accelerated the

679 recovery rate from Nav1.8 inactivation. The time constants estimated from single exponential fits were

$68029.71 \pm 2.54 \mathrm{~ms}$ (control), $5.81 \pm 1.03 \mathrm{~ms}$ (FHF2B, $\mathrm{p}<0.0001 v s$ control), $4.45 \pm 0.43 \mathrm{~ms}$ (FHF2A, $\mathrm{p}<$

$6810.0001 v s$ control) and $5.46 \pm 0.40 \mathrm{~ms}$ (FHF4A, p $<0.0001 v s$ control). (d) Family of classical currents

682 recorded from HEK293 cells expressing recombinant Nav1.9. Currents were elicited by 50-ms

683 depolarizing voltage steps from $+20 \mathrm{mV}$ to $-100 \mathrm{mV}$ in $-20 \mathrm{mV}$ increments from a holding potential of -

$684120 \mathrm{mV}$ (inset). (e) Effects of FHF2B, FHF2A and FHF4A on steady-state activation ( $\mathrm{p}=0.1832,0.0171$,

$6850.3215 v s$ control, respectively) and inactivation $(\mathrm{p}=0.175,0.5978,0.636 v s$ control, respectively) of

686 Nav1.9. (f), FHF2B, FHF2A and FHF4A did not affect the recovery rate from Nav1.9 inactivation. The

687 time constants estimated from single exponential fits were $38.46 \pm 4.64 \mathrm{~ms}$ (control), $48.99 \pm 6.93 \mathrm{~ms}$

688 (FHF2B, $\mathrm{p}=0.2041 v s$ control), $49.72 \pm 6.81 \mathrm{~ms}(\mathrm{FHF} 2 \mathrm{~A}, \mathrm{p}=0.1745 v s$ control) and $31.95 \pm 2.84 \mathrm{~ms}$

689 (FHF4A, $\mathrm{p}=0.4786 v s$ control). In (a-c), cells were pretreated with $500 \mathrm{nM}$ TTX. Filled circles, open

690 circles, open diamond and open squares represent control, FHF2B, FHF2A and FHF4A, respectively. The

691 number of separate cells tested is indicated in parentheses. Data points are shown as mean \pm S.E. The $V_{1 / 2}$

692 values for activation and inactivation are summarized in Table 1.

693 Figure 2. $I_{\mathrm{NaR}}$ were produced by recombinant Nav1.8 and Nav1.9 coexpressed with FHF2A or

694 FHF4A in heterologous systems. (a, e) Family of representative current traces recorded from cells

695 expressing Nav1.8 or Nav1.9that generated $I_{\mathrm{NaR}}$ in the presence of FHF4A (right) and that did not in the

696 absence of any FHFs (control, left). Currents were elicited by a standard resurgent current protocol shown 
in the inset. (b,f) Overlay of single current traces of Nav1.8 - Nav1.9 elicited by the protocol (inset) in the absence (control, black) or presence of FHF2B (red), FHF1A (yellow), FHF2A (blue), FHF3A (purple) and FHF4A (green). $(\mathbf{c}, \mathbf{g})$ Voltage dependence of the relative Nav1.8 and Nav1.9 $I_{\mathrm{NaR}}$ mediated by FHF1A - FHF4A. (d,h) The rise time (time to peak) and time constants of the decay kinetics of FHFmediated $I_{\mathrm{NaR}}$ in Nav1.8 and Nav1.9. While cells expressing Nav1.8 were held at $-100 \mathrm{mV}$, cells expressing Nav1.9 were at $-120 \mathrm{mV}$. The number of separate cells tested is indicated in parentheses. Data points are shown as mean \pm S.E.

Figure 2 - figure supplement 1. Extreme slow non-decay currents were caused by slow recovery from inactivation of Nav1.9 "window currents". (a) Typical current traces elicited by a modified standard $I_{\mathrm{NaR}}$ protocol, in which repolarizing phase was extended to be $1000 \mathrm{~ms}$ (inset). (b) Normalization of the nondecay currents to the peak transient current with maximum amplitude. The non-decay currents were measured after $990 \mathrm{~ms}$ into the depolarizing pulse. (c) Normalized steady state activation and inactivation. (d) Overlay of the curves for normalized non-decay currents (filled circles), steady-state activation and inactivation (dash lines). The number of separate cells tested is indicated in parentheses.

Figure 3. The peptides F2A and F4A fully reconstituted FHF2A/FHF4A-induced $I_{\mathrm{NaR}}$ in Nav1.8 and Nav1.9 in heterologous systems. (a) Schematic diagram of A- and B-type of FHFs (left). The amino acid sequences of short peptides located at $\mathrm{N}$ terminus of FHF2A and FHF4A are shown (right). Five

714 positively charged residues of interest are highlighted in bold. 5Q is a mutant of F2A, in which five

715 positive residues are replaced by $G \ln (\mathrm{Q})$. The residues conserved in F2A are indicated as dots. (b)

716 Overlay of representative Nav1.8 $I_{\mathrm{NaR}}$ traces in the absence (control, black) and presence of F2A (blue),

717 5Q (red) or F4A (green). (c) Voltage dependence of the relative F2A- and F4A-induced Nav1.8 $I_{\text {NaR. }}(\mathbf{d})$

718 Decay time constants $(\tau$, right $)$ of transient Nav1.8 currents $($ left $)$ at $+30 \mathrm{mV}$. The time constants $\left(\tau_{\text {fast }}, \tau_{\text {slow }}\right)$

719 were well fitted by a double exponential function. $\tau_{\text {fast }}$ : control, $2.35 \pm 0.40 \mathrm{~ms} ; \mathrm{F} 2 \mathrm{~A}, 0.92 \pm 0.09 \mathrm{~ms}(\mathrm{p}=$ $0.0037 v s$ control); 5Q, $1.26 \pm 0.07 \mathrm{~ms}(\mathrm{p}=0.0339 v s \mathrm{~F} 2 \mathrm{~A}) ; \mathrm{F} 4 \mathrm{~A}, 0.83 \pm 0.04 \mathrm{~ms}(\mathrm{p}=0.0071 v s$ control).

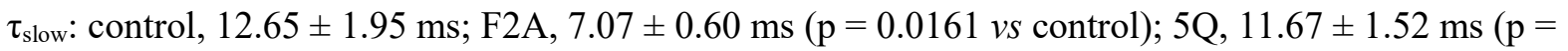


$0.0065 v s$ F2A); F4A, $3.72 \pm 0.28 \mathrm{~ms}\left(\mathrm{p}=0.0021 v s\right.$ control). (e) Overlay of Nav1.9 $I_{\mathrm{NaR}}$ traces in the absence (control, black) and presence of F2A (blue), 5Q (red) or F4A (green). (f) Voltage dependence of the relative F2A- and F4A-induced Nav1.9 $I_{\mathrm{NaR} .}(\mathbf{g})$ Decay time constants $(\tau$, right $)$ of transient Nav1.9 currents (left) at $+30 \mathrm{mV}$. The time constants were fitted well by a single exponential function. Cells expressing Nav1.8 or Nav1.9 were held at $-100 \mathrm{mV}$ or $-120 \mathrm{mV}$, respectively. All $I_{\mathrm{NaR}}$ of Nav1.8 or Nav1.9 were normalized to the peak transient current at $-40 \mathrm{mV}$ or at $0 \mathrm{mV}$, respectively. The concentrations of F2A, 5Q and F4A all are $1 \mathrm{mM}$. Filled and open circles represent FHF2A and FHF4A, respectively. The number of separate cells tested is indicated in parentheses. ${ }^{*}, \mathrm{p}<0.05 ; * *, \mathrm{p}<0.01$.

Figure 4. Nav1.9 $I_{\mathrm{NaR}}$ generated from Nav1.8 knockdown DRG neurons. (a), Typical Nav1.9 current traces induced by the protocol (inset), in which cells were subjected to 50-ms depolarization of potentials ranging from -120 to $+40 \mathrm{mV}$ with a $10-\mathrm{mV}$ increment from a holding potential of $-120 \mathrm{mV}$. (b,c), Representative current traces recorded from DRG neurons that did (b) and that did not (c) generate $I_{\mathrm{NaR}}$. Currents were elicited by a standard $I_{\mathrm{NaR}}$ protocol (inset), where cells were initially depolarized to +30 $\mathrm{mV}$ for $20 \mathrm{~ms}$, then followed by a 100-ms hyperpolarizing potential ranging from +10 to $-100 \mathrm{mV}$. (d), Voltage dependence of Nav1.9 $I_{\mathrm{NaR}}$ shown in (b). All $I_{\mathrm{NaR}}$ were normalized to peak transient current. (e), Steady-state activation and inactivation measured on DRG neurons with or without $I_{\mathrm{NaR}}$.

Figure 5. FHF4 knockdown reduced the ability of Nav1.8 to generate $I_{\mathrm{NaR}}$ in rat DRG neurons. (a) Immunofluorescent reactions showed expression levels of FHF4 in DRG neurons. Dashed lines show the shape of transfected DRG neurons. Scale bars, $50 \mu \mathrm{m}$; ab, antibody. (b) Summary of fluorescence in DRG neurons transfected with the scrambled shRNA or FHF4shRNA $(\mathrm{p}<0.0001)$. (c) FHF4 knockdown did not significantly alter Nav1.8 current density $(\mathrm{p}=0.9116)$. (d) FHF4 knockdown shifted voltage dependence of steady-state inactivation to more negative potentials $(\mathrm{p}<0.0001)$, but did not affect activation $(\mathrm{p}=0.9116)$. (e) FHF4 knockdown did not significantly impair the recovery rate from inactivation The time constants estimated from single exponential fits were $2.92 \pm 0.53 \mathrm{~ms}$ (scramble) and $4.00 \pm 1.01 \mathrm{~ms}(\mathrm{FHF} 4 \mathrm{shRNA}, \mathrm{p}=0.3905),$. (f) $I_{\mathrm{NaR}}$ traces recorded from small diameter DRG neurons 
747

748

749

750

751

752

753

754

755

756

757

758

759

760

761

762

763

764

765

transfected with scramble or FHF4shRNA. (g) FHF4 knockdown decreased the percentage of DRG neurons to generate Nav1.8 $I_{\mathrm{NaR}}(\mathrm{p}<0.0001)$. (h) Voltage dependence of the relative Nav1.8 $I_{\mathrm{NaR}}$ in DRG neurons treated with scramble and FHF4shRNA. Filled and open circles represent scramble and FHF4shRNA, respectively. The number of separate cells tested is indicated in parentheses. N.S, not significant; $*, p<0.05 ; * * *, p<0.0001$.

Figure 5 - figure supplement 1. FHF4 knockdown did not influence Nav $\beta 4$ expression in DRG neurons. The number of separate cells tested is indicated in parentheses. N.S, not significant.

Figure 6. FHF4shRNA-mediated reduction in DRG neuron excitability was rescued by the F4A peptide. (a) Typical single action potentials elicited by a 1-ms current injection. (b) Resting membrane potentials under scramble, FHF4shRNA and FHF4shRNA + F4A ( $p=0.6149$, one-way ANOVA). (c) Summary of current threshold ( $p=0.9673$, one-way ANOVA). (d) Summary of action potential duration (APD90). The durations were $17.94 \pm 2.63 \mathrm{~ms}$ (scramble), $10.54 \pm 1.19 \mathrm{~ms}$ (FHF4shRNA, $\mathrm{p}=0.0153 v s$ control) and $14.76 \pm 1.22 \mathrm{~ms}(+\mathrm{F} 4 \mathrm{~A}, \mathrm{p}=0.0233 v s$ FHF4shRNA and $\mathrm{p}=0.3011$ vs control), respectively. (e) Typical action potential trains elicited by a 2-s injection of 400-pA current. (f) Summary of the number of action potentials elicited by a 2-s injection of currents ranging from $0-800 \mathrm{pA}$. (g) F4A did not alter Nav1.8 current density $(\mathrm{p}=0.8428)$. (h) Voltage dependence of activation and steady-state inactivation of Nav1.8 before and after addition of F4A in FHF4shRNA-treated DRG neurons (activation: $\mathrm{p}=0.8160$; inactivation: $\mathrm{p}=0.0332$ ). (i) F4A did not impair the recovery rate from Nav1.8 inactivation in FHF4shRNA-treated DRG neurons. The time constants estimated from single exponential fits were 4.00 $\pm 1.01 \mathrm{~ms}(\mathrm{FHF} 4 \mathrm{shRNA})$ and $2.92 \pm 0.42 \mathrm{~ms}(+\mathrm{F} 4 \mathrm{~A}, \mathrm{p}=0.5826)$, respectively. $(\mathbf{j}) \mathrm{F} 4 \mathrm{~A}$ increased the percentage of FHF4shRNA-treated DRG neurons to generate Nav1.8 $I_{\mathrm{NaR}}(\mathrm{p}=0.0066)$. (k) F4A increased the relative amplitude of Nav1.8 $I_{\mathrm{NaR}}$ in FHF4shRNA-treated DRG neurons $(\mathrm{p}=0.0027)$. In $(\mathbf{a}-\mathbf{k})$, the concentration of F4A is $1 \mathrm{mM}$. Filled circles, open circles and open squares represent scramble, FHF4shRNA and F4A, respectively. The number of separate cells tested is indicated in parentheses. The $\mathrm{V}_{1 / 2}$ values measured in (h) were summarized in Table 2 . N.S, not significant; ${ }^{*}, \mathrm{p}<0.05 ; * * *, \mathrm{p}<0.001$. 
772 Figure 7. Navß4 peptide did not induce Nav1.9 I $_{\mathrm{NaR}}$ in HEK293 cells. (a) Overlay of normalized

773 current traces elicited by a resurgent protocol (inset) in the absence (control, grey) and presence of 200

$774 \mu \mathrm{M}$ Navß4 peptide (black). (b) Voltage dependence of the relative currents. Filled and open circles

775 represent control and Navß4 peptide, respectively.

Figure 8. The residue at position 799 in Nav1.9 was crucial for VGSC sensitivity to Navß4. (a)

777 Sequence alignment of domain II S6 segments of Nav1.5 - Nav1.9. The position of the residues of interest

778 is indicated in bold and designated with a number. (b) The K799N mutation and the reversal mutation

779 N927K did not significantly alter steady-state activation or inactivation of Nav1.9 (circles, right) and

780 Nav1.5 (squares, left), respectively. (c) The Nav1.9 mutant K799N generated $I_{\mathrm{NaR}}$ in the presence of 200

$781 \mu \mathrm{M} \mathrm{Nav \beta 4}$ peptide (black). Control, grey. (d) Voltage dependence of the relative $I_{\mathrm{NaR}}$ in the Nav1.9

782 mutant K799N (filled circles). (e) Typical $I_{\mathrm{NaR}}$ traces recorded from Nav1.9 (black) and the mutant

$783 \mathrm{~K} 799 \mathrm{~N}$ (grey) in the presence of $1 \mathrm{mM}$ F2A. (f) Comparison of the relative F2A-induced $I_{\text {NaR. }}$. Filled and

784 open circles represent Nav1.9 and the mutant K799N, respectively. (g) Typical $I_{\mathrm{NaR}}$ traces recorded from

785 Nav1.5 (black) and the mutant N927K (grey) in the presence of $200 \mu \mathrm{M}$ Navß4 peptide. (h) Voltage

786 dependence of the relative $I_{\mathrm{NaR}}$ in Nav1.5 (filled squares) and the mutant N927K (open squares). (i)

787 Typical $I_{\mathrm{NaR}}$ traces recorded from Nav1.5 (black) and the mutant N927K (grey) in the presence of FHF2A.

788 (j) Comparison of the relative FHF2A-induced $I_{\mathrm{NaR}}$ in Nav1.5 (filled squares) and the mutant N927K

789 (open squares). In (c,e,g,i), $I_{\mathrm{NaR}}$ were elicited by the protocols shown in the inset. In (b,c,d,g,h), $500 \mu \mathrm{M}$

790 GTP- $\gamma-\mathrm{S}$ was added for Nav1.9 and K799N cells in the pipette solution. F2A and Navß4 peptide were

791 applied in peptide solution. The number of separate cells tested is indicated in parentheses. ${ }^{* *}, \mathrm{p}<0.005$.

792 Figure 8 - figure supplement 1. The N945K mutation substantially reduced Nav $\beta 4$-mediated Nav1.7

$793 I_{\mathrm{NaR}}$ in HEK293 cells. Typical $I_{\mathrm{NaR}}$ traces in the presence of $200 \mu \mathrm{M}$ Nav $\beta 4$ peptide were elicited by the

794 protocol shown in inset. Nav1.7, black; N945K, grey. 
Figure 9. $I_{\mathrm{NaR}}$ were produced by recombinant Nav1.5 and Nav1.7 coexpressed with FHF2A in

heterologous systems. (a,d,e) Family of representative current traces recorded from cells expressing

797 Nav1.5, Nav1.7, or Nav1.6 in the presence of FHF2A (below) and that did not in the absence of any FHFs

798 (control, upper). Currents were elicited by a standard $I_{\mathrm{NaR}}$ protocol shown in the inset. (b,e,h) Overlay of 799 single current traces of Nav1.5 - Nav1.7 elicited by the protocol (inset) in the absence (control, black) or 800 presence of FHF2B (red), FHF2A (blue) and FHF4A (green). (c,f) Voltage dependence of the relative

801 Nav1.5 and Nav1.7 $I_{\mathrm{NaR}}$ mediated by FHF2A. (i) The rise time and time constants of the decay kinetics of 802 FHF2A-mediated $I_{\mathrm{NaR}}$ in Nav1.5 and Nav1.7. In (c,f), all $I_{\mathrm{NaR}}$ were normalized to the peak transient 803 current. In (i), time constants were obtained by fitting a single exponential function. Cells were held at $804120 \mathrm{mV}$. The number of separate cells tested is indicated in parentheses. Data points are shown as mean \pm 805 S.E.

Figure 10. FHF4A induces long-term inactivation, not $\boldsymbol{I}_{\mathrm{NaR}}$, in Nav1.6 channels. HEK293 cells stably

807 expressing human Nav1.6 were recorded under control conditions, after FHF4A transfection and with

808 F4A peptide $(1 \mathrm{mM})$ in the pipette solution. (a) Both the full-length FHF4A and the F4A peptide induced

809 a substantial increase in long-term inactivation in response to a train of six $-20 \mathrm{mV}$ depolarizations at $\sim 50$ Hz. (b) Neither full-length FHF4A nor F4A peptide induced detectable $I_{\mathrm{NaR}}$ in HEK293 cells expressing

811 Nav1.6 channels. For comparison, data for Nav1.6 $I_{\mathrm{NaR}}$ with Nav $\beta 4$ peptide $(200 \mathrm{mM})$ is shown with the 812 dashed curve, adapted from Pan and Cummins (2020). 
Tables

Table 1. Gating properties of Nav1.8 and Nav1.9 in the presence of FHFs

\begin{tabular}{cccccc}
\hline construct & $\mathbf{V}_{\mathbf{1} / \mathbf{2}}(\mathrm{mV})$ & control & FHF2A & FHF2B & FHF4A \\
\hline Nav1.8 & activation & $-2.4 \pm 1.5(9)$ & $-12.4 \pm 2.7^{@}(8)$ & $-18.5 \pm 2.7^{@}(7)$ & $-9.0 \pm 1.9^{*}(12)$ \\
& inactivation & $-59.6 \pm 1.8(9)$ & $-37.9 \pm 1.9^{@}(8)$ & $-44.3 \pm 2.3^{@}(7)$ & $-39.0 \pm 2.2^{@}(12)$ \\
Nav1.9 & activation & $-47.8 \pm 2.5(10)$ & $-46.0 \pm 1.2(8)$ & $-50.9 \pm 2.0(11)$ & $-50.5 \pm 4.8(6)$ \\
& inactivation & $-55.2 \pm 2.3(10)$ & $-45.9 \pm 2.5^{*}(8)$ & $-53.2 \pm 4.2(11)$ & $-45.2 \pm 4.3(6)$ \\
\hline
\end{tabular}

Midpoint voltages of the steady-state activation and inactivation curves in Fig. S1 were determined with a standard Boltzmann distribution fit. ${ }^{*} \mathrm{p}<0.05$, ${ }^{\#} \mathrm{p}<0.01$ and ${ }^{\circledR} \mathrm{p}<0.001$ versus respective control condition. The number of separate cells tested is indicated in parentheses.

Table 2. Gating properties of Nav1.8 in DRG neurons

\begin{tabular}{cccr}
\hline $\mathbf{V}_{\mathbf{1} / \mathbf{2}}$ & Control $(\mathrm{mV})$ & FHF4shRNA & +F4A 822 \\
\hline activation & $-11.1 \pm 1.1(14)$ & $-10.7 \pm 2.9(18)$ & $-9.3 \pm 3.5(10)$ \\
inactivation & $-28.5 \pm 1.0(14)$ & $-40.4 \pm 2.0^{@}(18)$ & $-35.9 \pm 1.2^{@}(805)$ \\
\hline
\end{tabular}

Midpoint voltages of the steady-state activation and inactivation curves in Figures 4 and 5 were determined with a standard Boltzmann distribution fit. ${ }^{a} \mathrm{p}<0.001$ versus respective control condition. The number of separate cells tested is indicated in parentheses.

Table 3. Gating properties of wild-type Nav1.5, the mutant N927K, wild-type Nav1.9 and the mutant K799N.

\begin{tabular}{ccccr}
\hline $\mathbf{V}_{\mathbf{1} / 2}(\mathrm{mV})$ & Nav1.5wt & N927K & Nav1.9wt & K799N 834 \\
\hline activation & $-44.6 \pm 4.4(5)$ & $-44.0 \pm 2.9(5)$ & $-37.1 \pm 3.3(5)$ & $-37.5 \pm 4.1(5)$ \\
inactivation & $-88.5 \pm 6.4(5)$ & $-89.7 \pm 0.9(5)$ & $-45.7 \pm 1.9(7)$ & $-44.0 \pm 1.5(886$ \\
\hline
\end{tabular}

Midpoint voltages of the steady-state activation and inactivation curves in Fig. S1 were determined with a standard Boltzmann distribution fit. ${ }^{*} \mathrm{p}<0.05$, ${ }^{*} \mathrm{p}<0.01$ and ${ }^{\circledR} \mathrm{p}<0.001$ versus respective control condition. The number of separate cells tested is indicated in parentheses. 
bioRxiv preprint doi: https://doi org/10.1101/2022 03.04.482974; this version posted March 5, 2022 . The copyright holder for this preprint (which was not certified by peer review) is the author/funder, who has granted bioRxiv a license to display the preprint in perpetuity. It is made available under aCC-BY 4.0 International license.

\section{Figure 1}

a
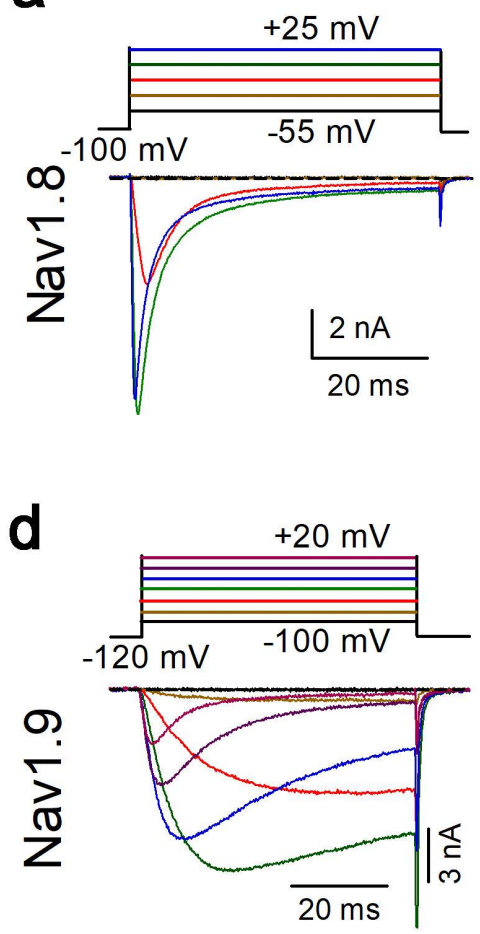

b

- control $(9) \quad \diamond$ FHF2A (8)

$\rightarrow$ FHF2B (7) $\quad$ FHF4A (12)

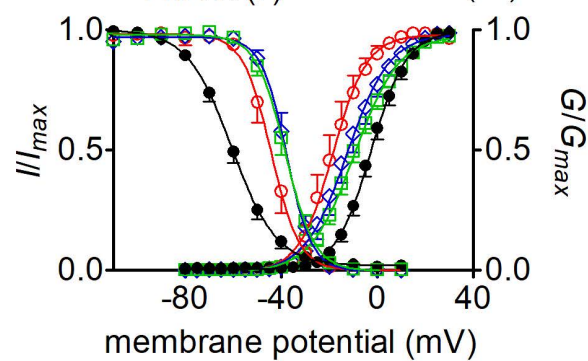

e $-\operatorname{control}(10) \diamond \mathrm{FHF} 2 \mathrm{~A}(8)$

$\diamond$ FHF2B (11) $\square$ FHF4A (6)

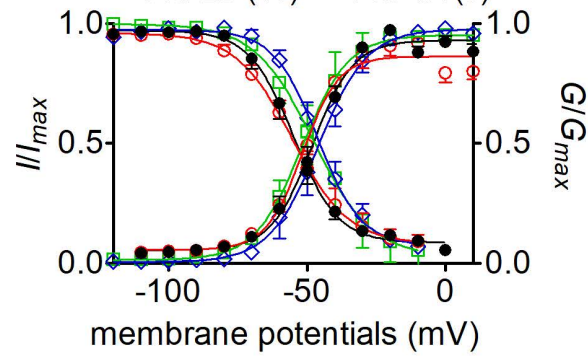

C

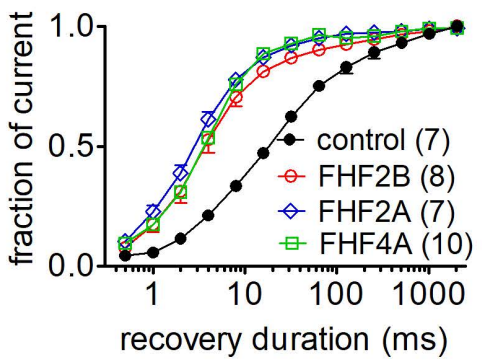

f

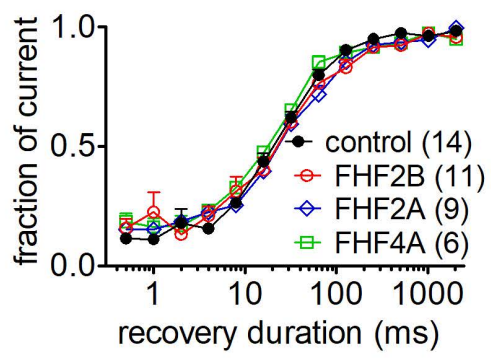


bioRxiv preprint doi: https://doi.org/10.1101/2022.03.04.482974: this version posted March 5, 2022. The copyright holder for this preprint (which was not certified by peer review) is the author/funder, who has granted bioRxiv a license to display the preprint in perpetuity. It is made available under aCC-BY 4.0 International license.

\section{Figure 2}

a
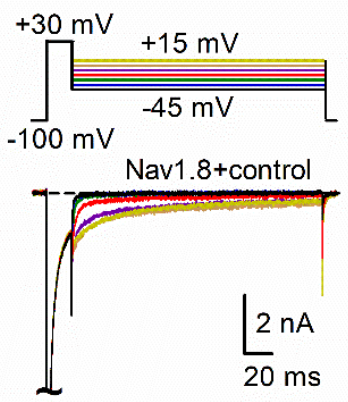

b

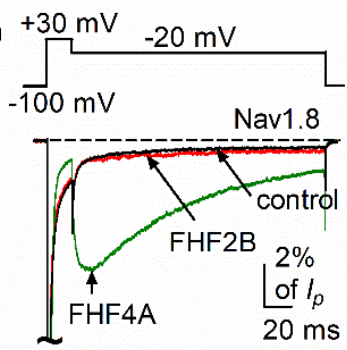

C

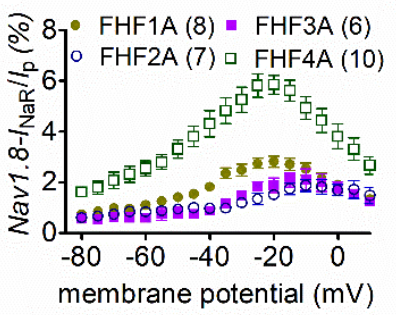

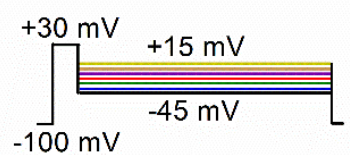

Nav1.8+FHF4A
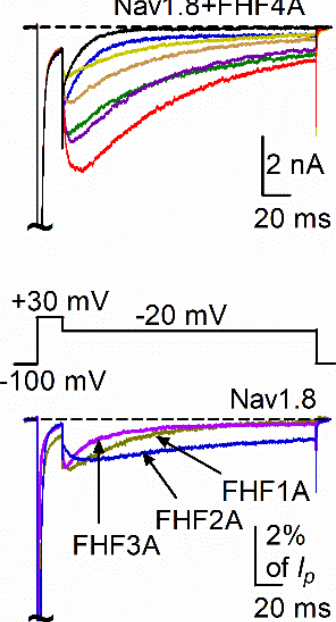

d

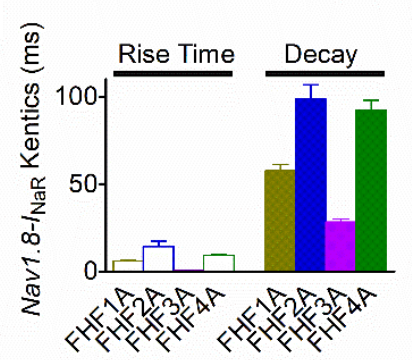

e
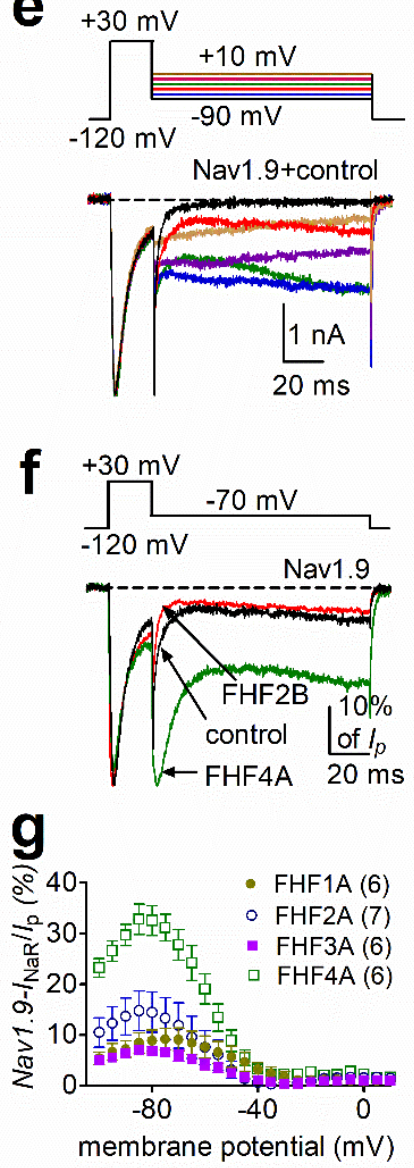
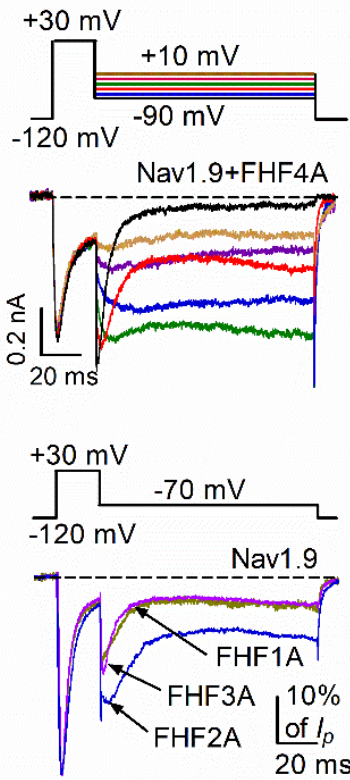

$\mathbf{h}$

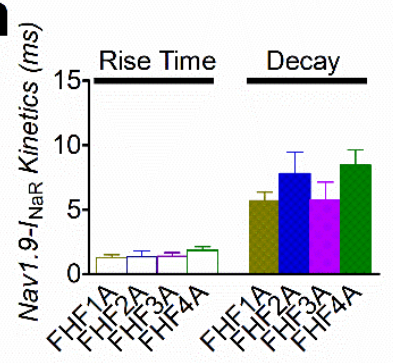


bioRxiv preprint doi: https://doi.org/10 1101/2022.03.04.482974 this version posted March 5, 2022. The copyright holder for this preprint (which was not certified by peer review) is the author/funder, who has granted bioRxiv a license to display the preprint in perpetuity. It is made available under aCC-BY 4.0 International license.

\section{Figure 2 - figure supplement 1}
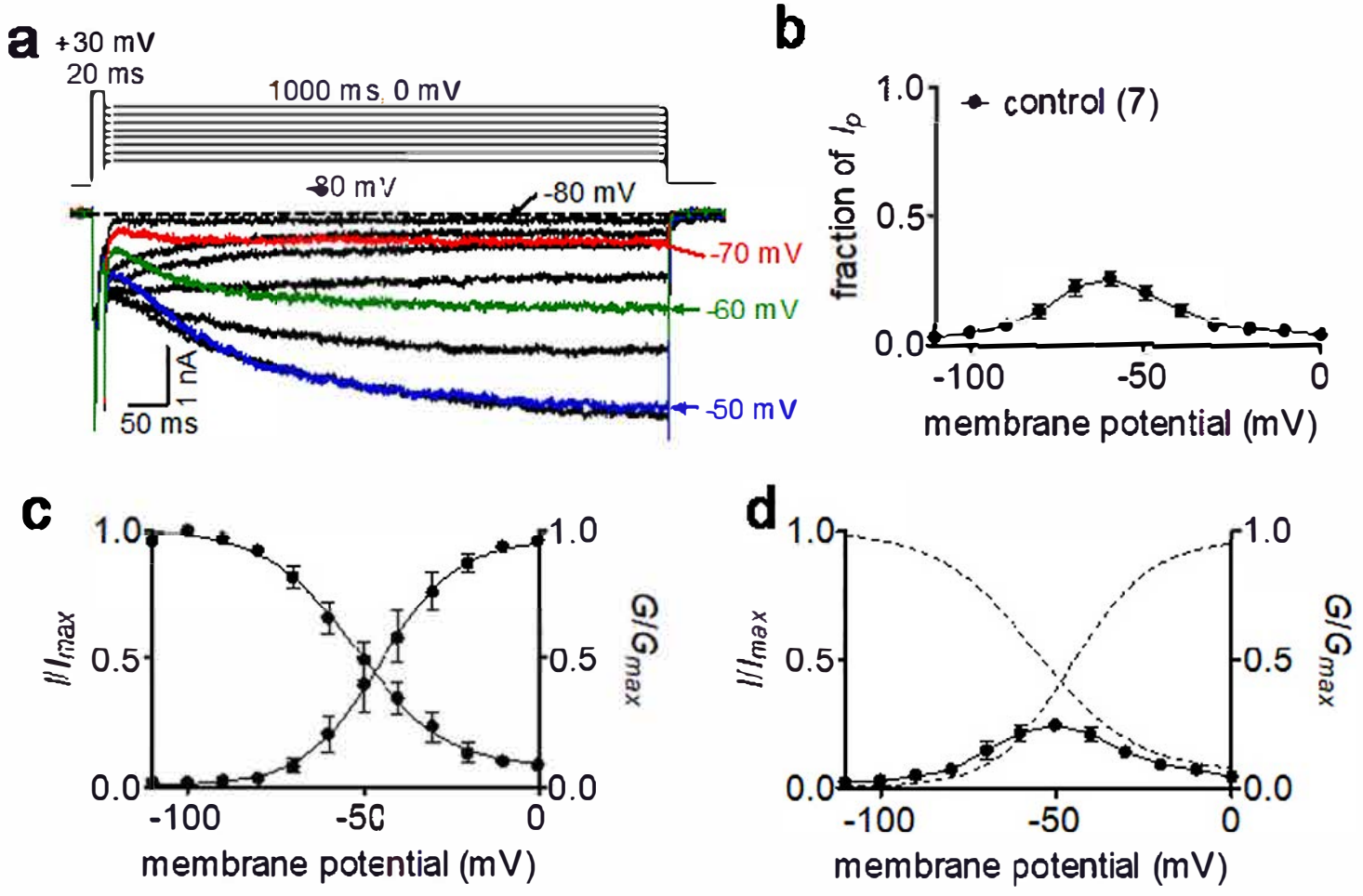
bioRxiv preprint doi: https://doi.org/10.1101/2022.03.04.482974: this version posted March 5, 2022. The copyright holder for this preprint (which was not certified by peer review) is the author/funder, who has granted bioRxiv a license to display the preprint in perpetuity. It is made available under aCC-BY 4.0 International license.

\section{Figure 3}

a

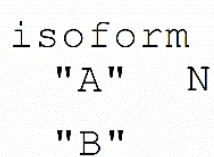

b

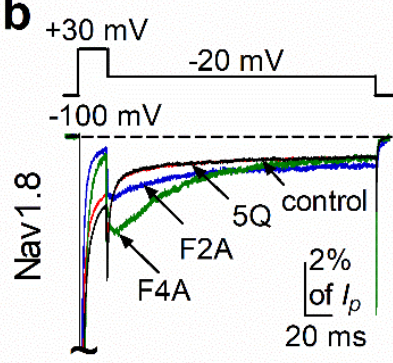

e

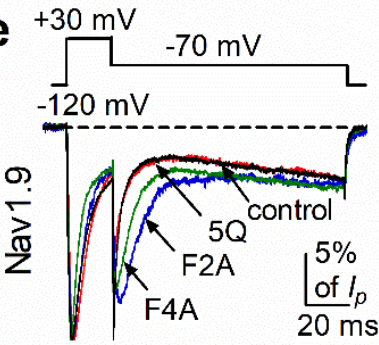

$\beta$-Trefoil

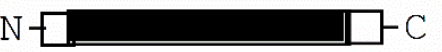

C

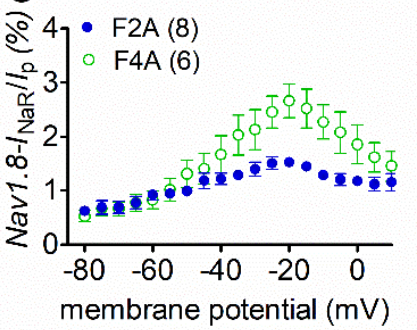

f

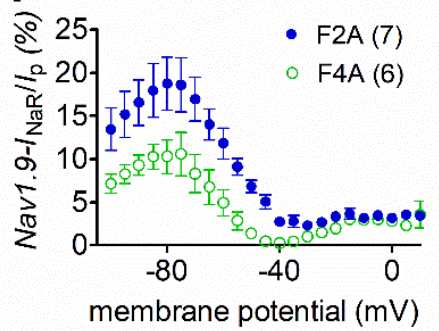

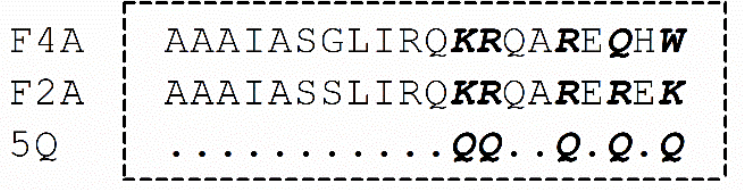

d

$+30 \mathrm{mV}$
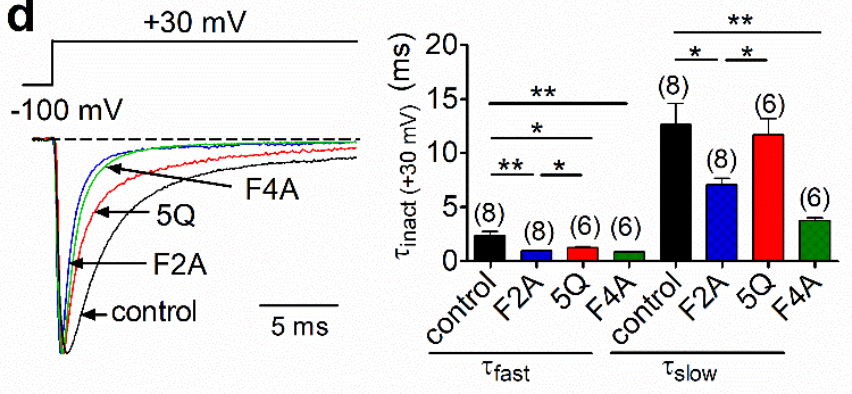

g
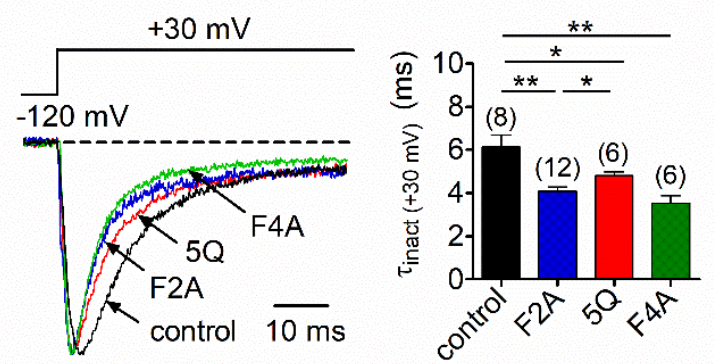


\section{Figure 4}
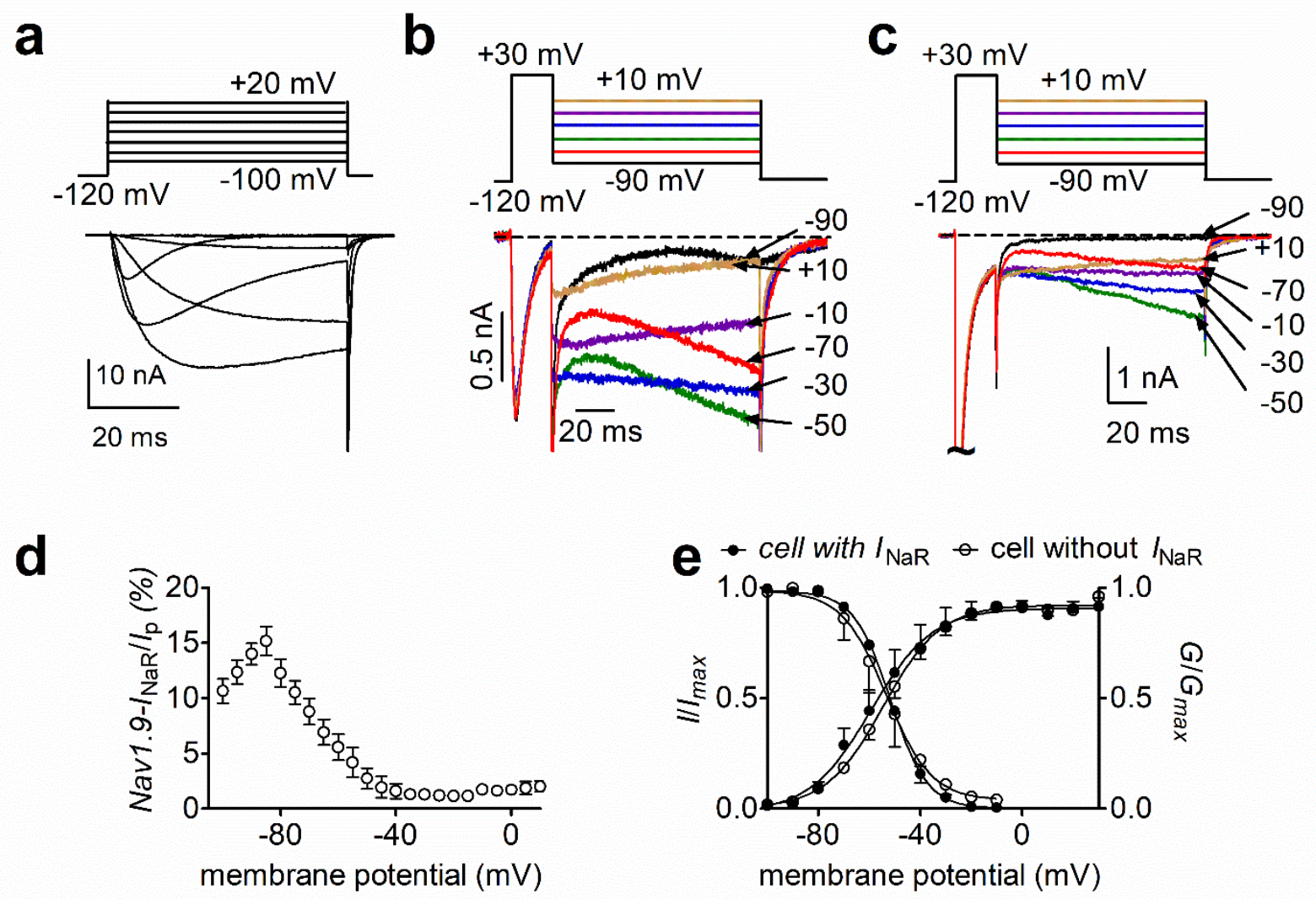
bioRxiv preprint doi: https://doi.org/10.1101/2022.03.04.482974; this version posted March 5, 2022. The copyright holder for this preprint (which was not certified by peer review) is the author/funder, who has granted bioRxiv a license to display the preprint in perpetuity. It is made available under aCC-BY 4.0 International license.

\section{Figure 5}

a

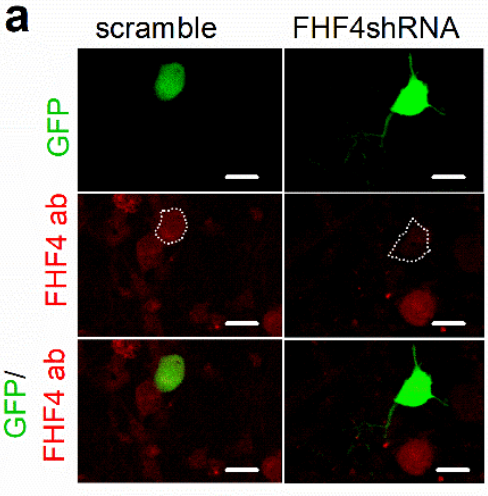

e

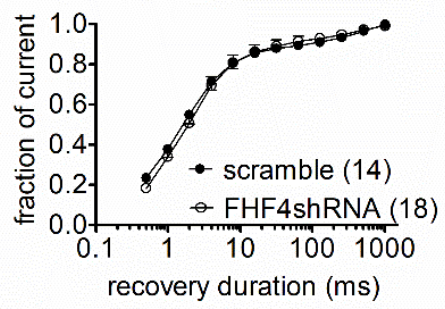

b

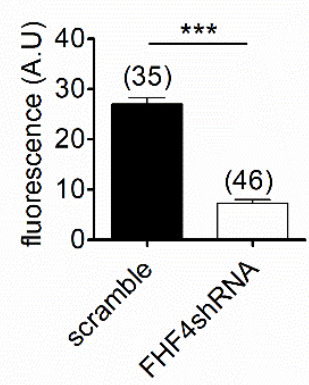

f $+30 \mathrm{mV}$

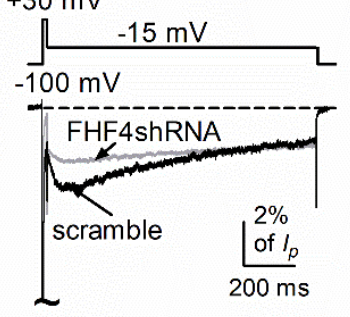

C

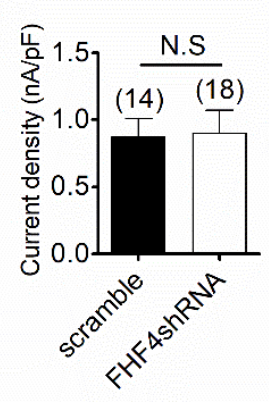

9

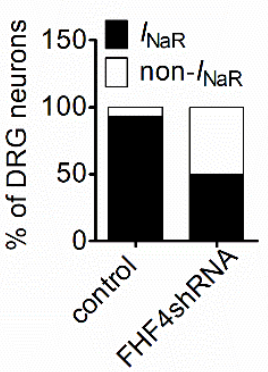

d

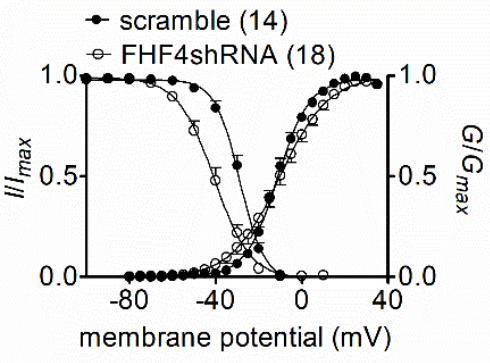

h

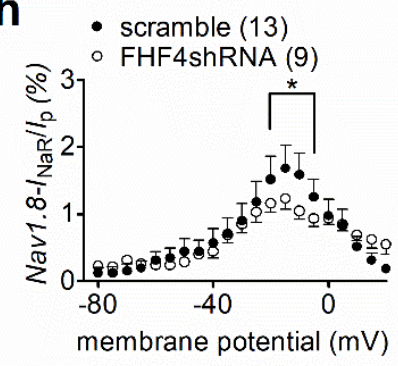


Figure 5 - figure supplement 1

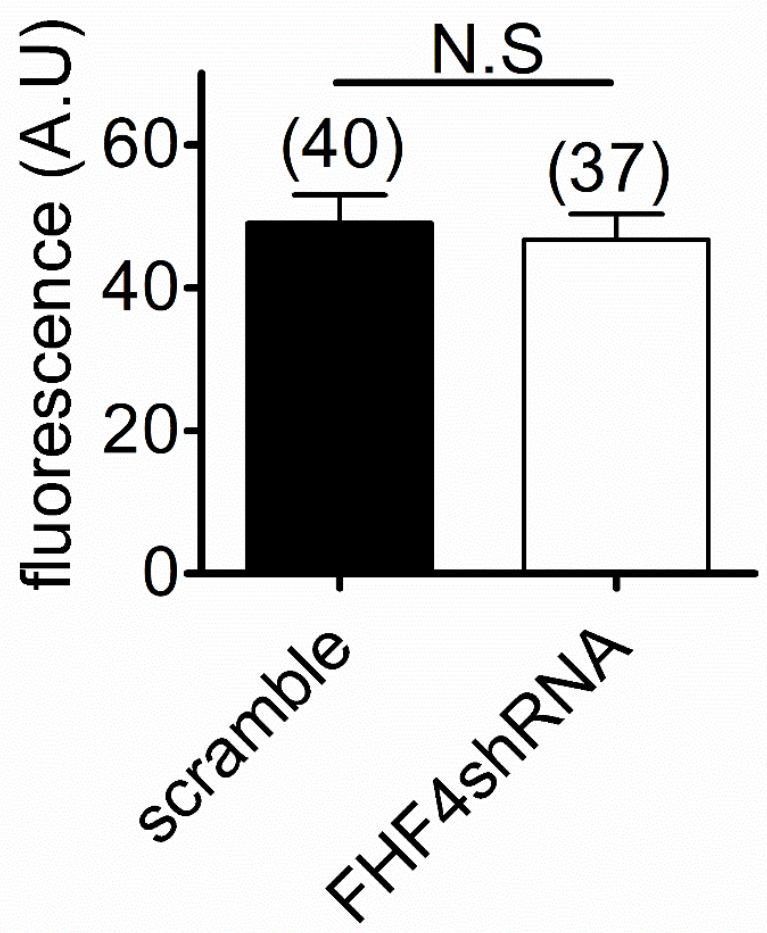


bioRxiv preprint doi: https://doi.org/10.1101/2022.03.04.482974; this version posted March 5, 2022. The copyright holder for this preprint (which was not certified by peer review) is the author/funder, who has granted bioRxiv a license to display the preprint in perpetuity. It is made available under aCC-BY 4.0 International license.

\section{Figure 6}

a

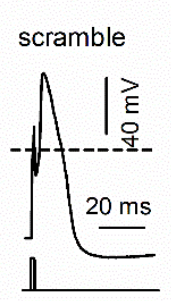

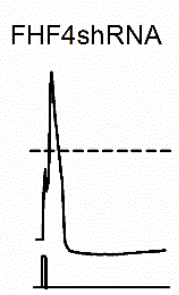

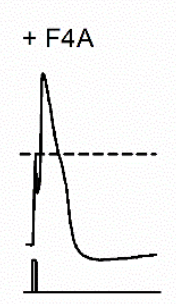

b

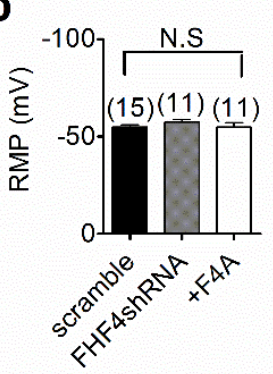

e

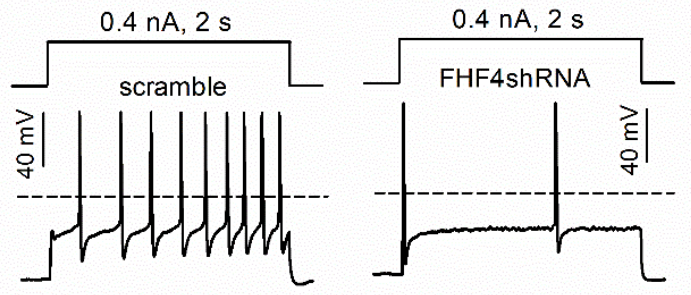

g

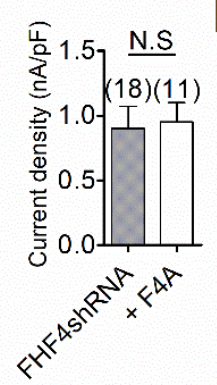

$h_{\ominus \text { FHF4ShRNA (18) } \square+F 4 A(10)}$

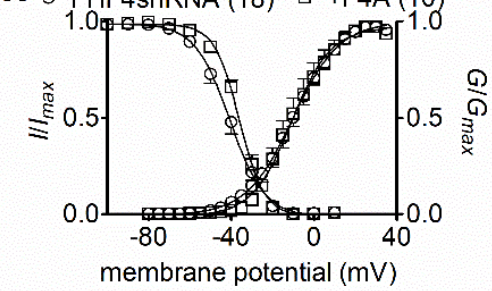

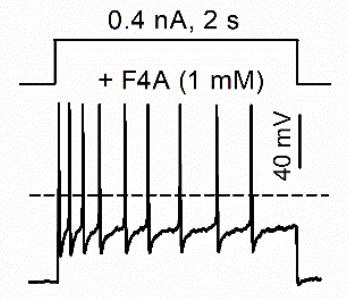

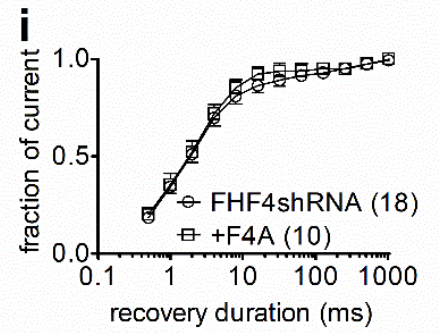

c
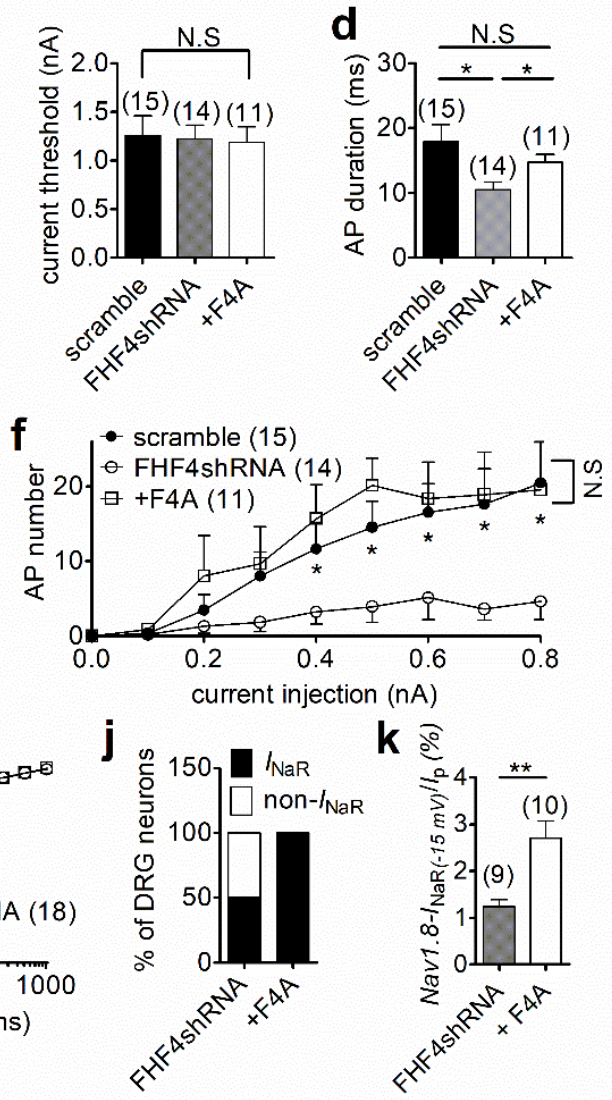

$k$ อ

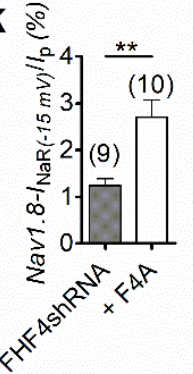


bioRxiv preprint doi: https://doi org/10 1101/2022 03.04 482974 this version posted March 5, 2022. The copyright holder for this preprint (which was not certified by peer review) is the author/funder, who has granted bioRxiv a license to display the preprint in perpetuity. It is made available under aCC-BY 4.0 International license.

\section{Figure 7}

a

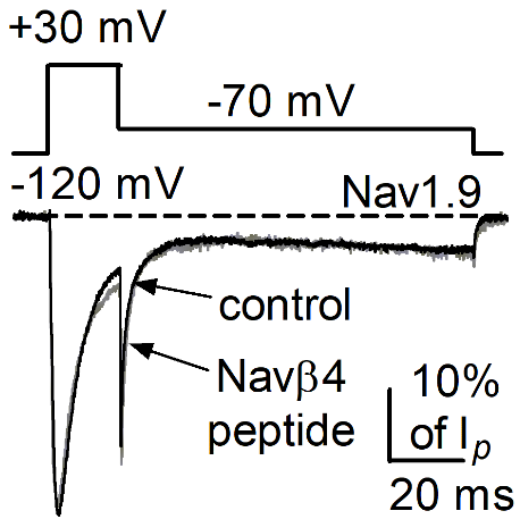

b

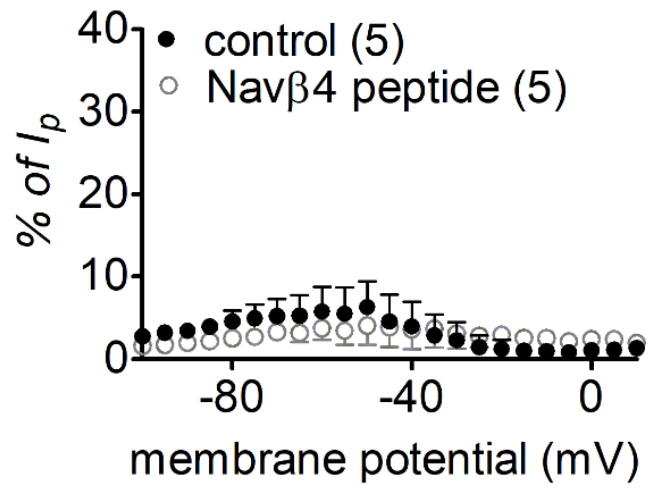


bioRxiv preprint doi: https://doi.org/10.1101/2022.03.04.482974; this version posted March 5, 2022. The copyright holder for this preprint (which was not certified by peer review) is the author/funder, who has granted bioRxiv a license to display the preprint in perpetuity. It is made available under aCC-BY 4.0 International license.

\section{Figure 8}

a

D2-S6

Nav1.5 CLLVFLLVMVIGNLVVLNLFLALLL

Nav1. 6 CLIVFMMVMVIGNLVVLNLFLALLL

NaV1. 7 CLIVYMMVMVIGNLVVLNLFLALLL

Nav1.8 CLILFLTVMVLGNLVVLNLFIALLL

Nav1.9 CVIVFILITVIGRLVVLNLFIALLL

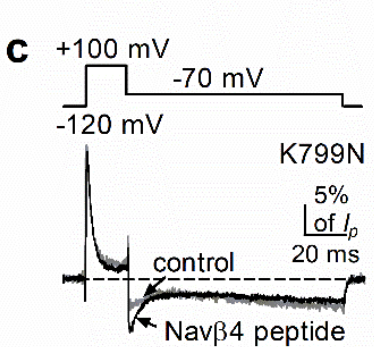

d

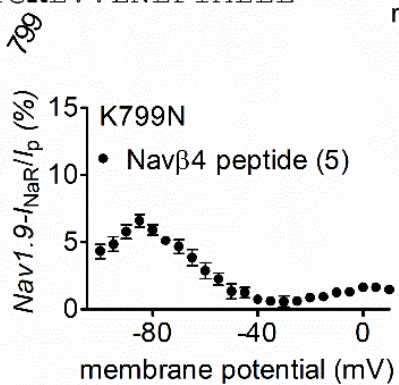

g

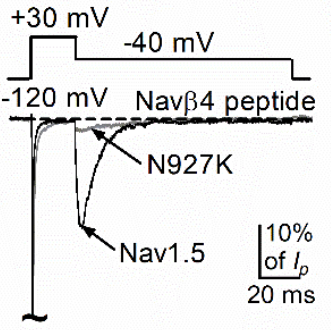

h

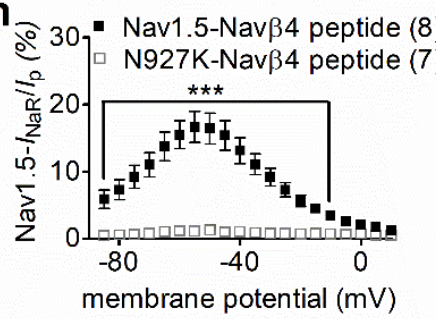

b $-\operatorname{Nav1} 1.9(5) \rightarrow K 799 N(5)$

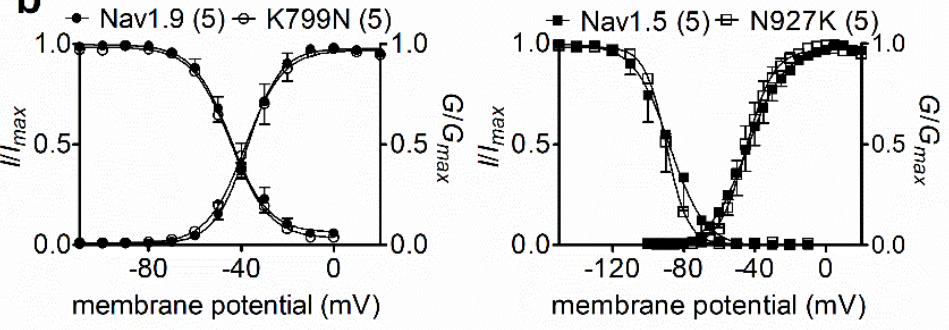

e $+30 \mathrm{mV}$

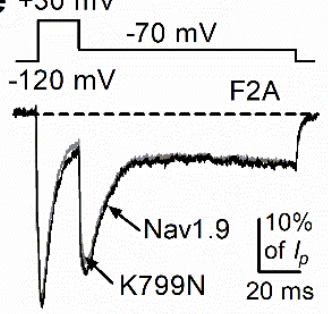

f

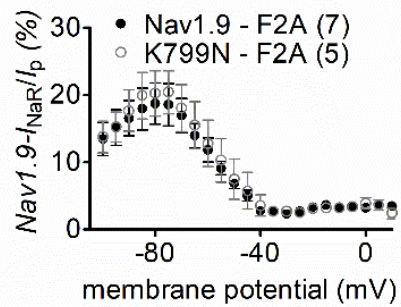

i

Nav1.5

$0.2 \%$

of $I_{p}$

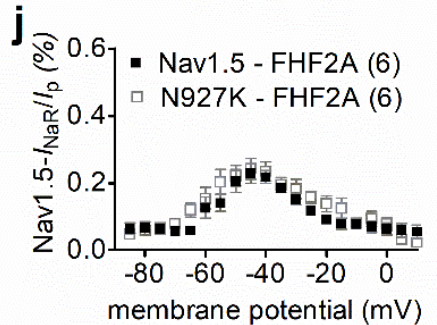


Figure 8 - figure supplement 1

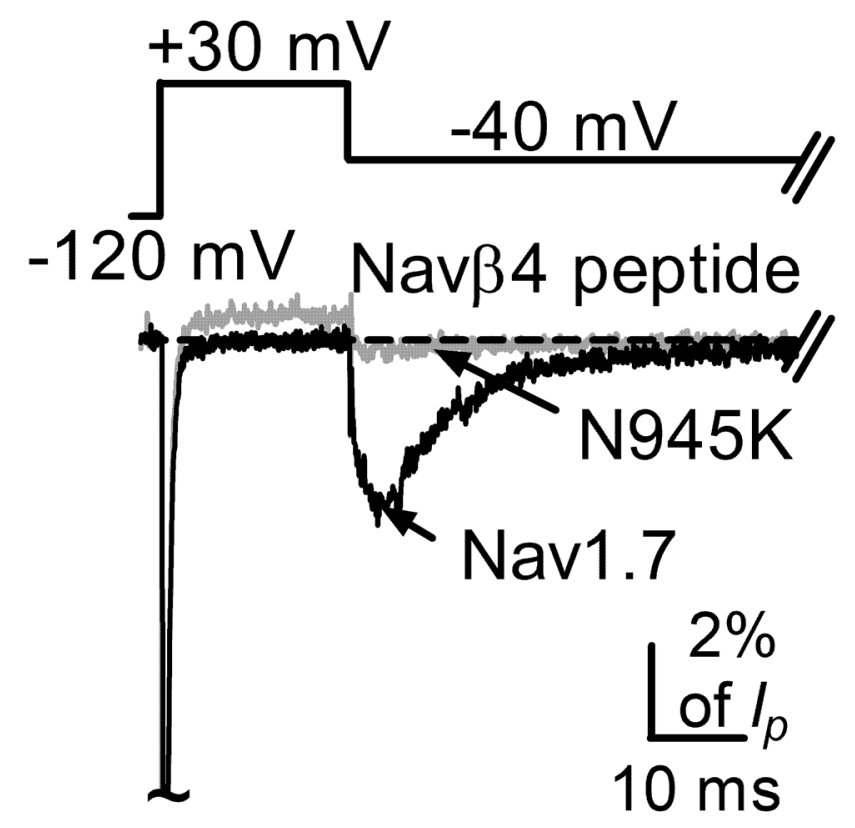


bioRxiv preprint doi: https://doi.org/10.1101/2022.03.04.482974; this version posted March 5, 2022. The copyright holder for this preprint (which was not certified by peer review) is the author/funder, who has granted bioRxiv a license to display the preprint in perpetuity. It is made available under aCC-BY 4.0 International license.

Figure 9

a

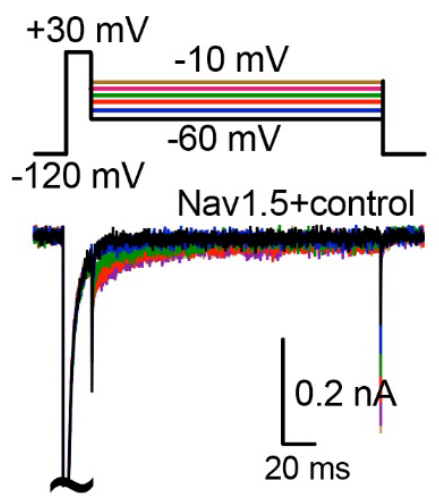

Nav1.5+FHF2A

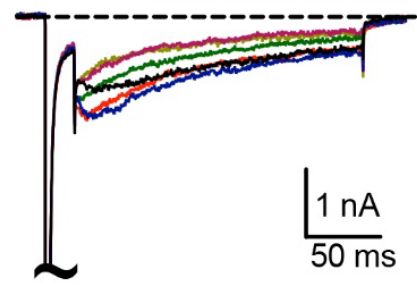

b
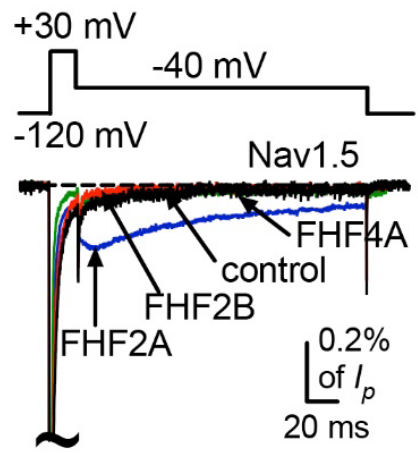

C

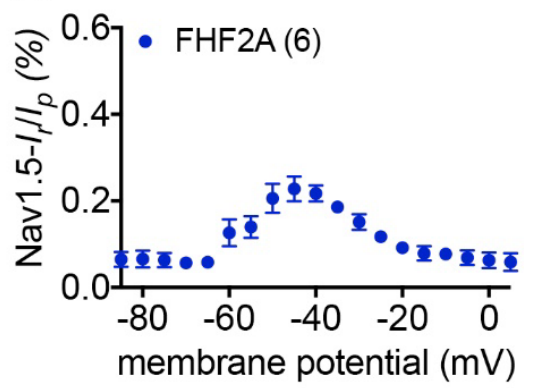

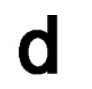

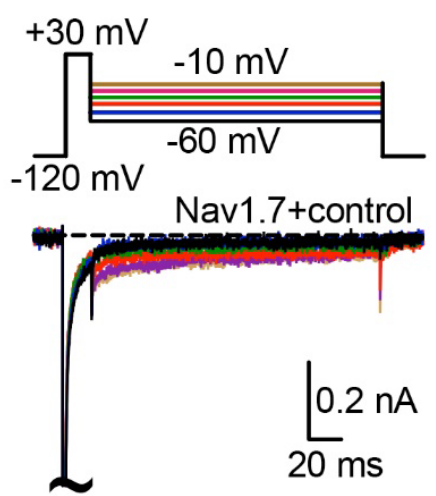

Nav1.7+FHF2A

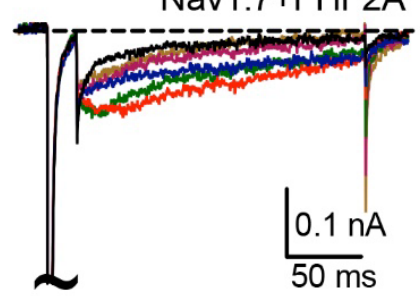

e
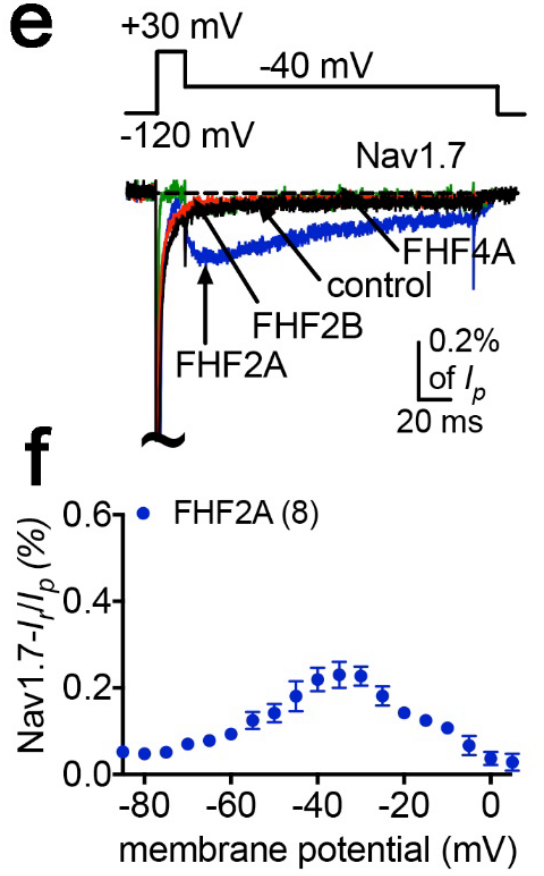

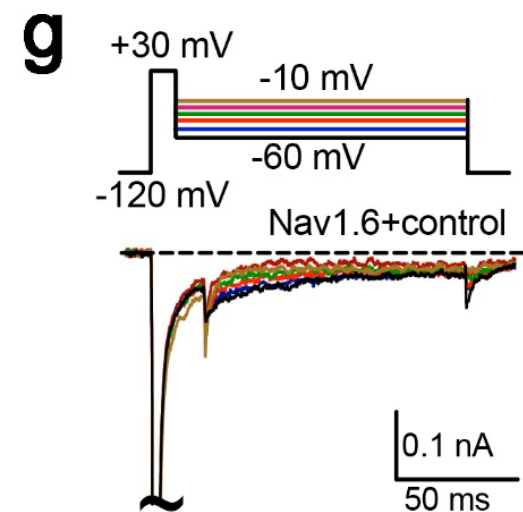

Nav1.6+FHF2A

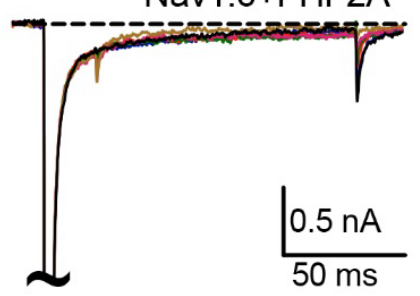

h $+30 \mathrm{mV}$
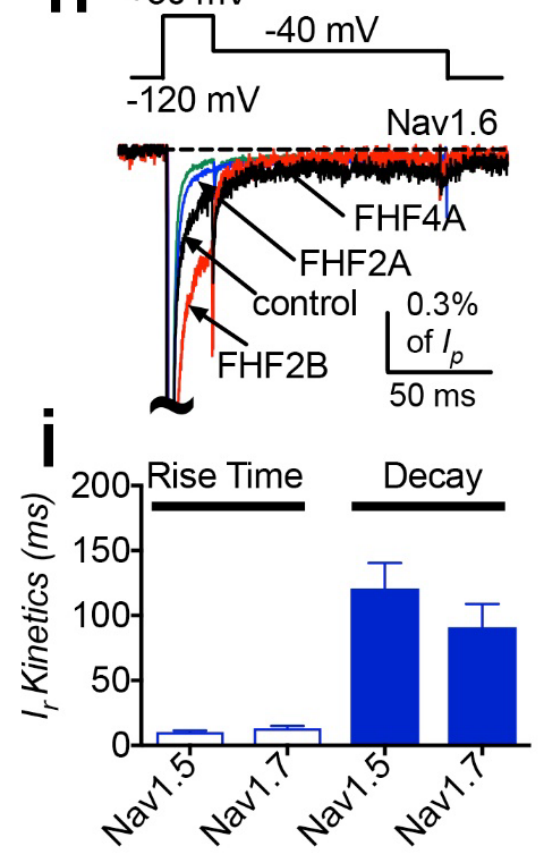
bioRxiv preprint doi: https://doi org/10.1101/2022 03.04 482974 this version posted March 5, 2022. The copyright holder for this preprint (which was not certified by peer review) is the author/funder, who has granted bioRxiv a license to display the preprint in perpetuity. It is made available under aCC-BY 4.0 International license.

Figure 10

A Long-Term Inactivation
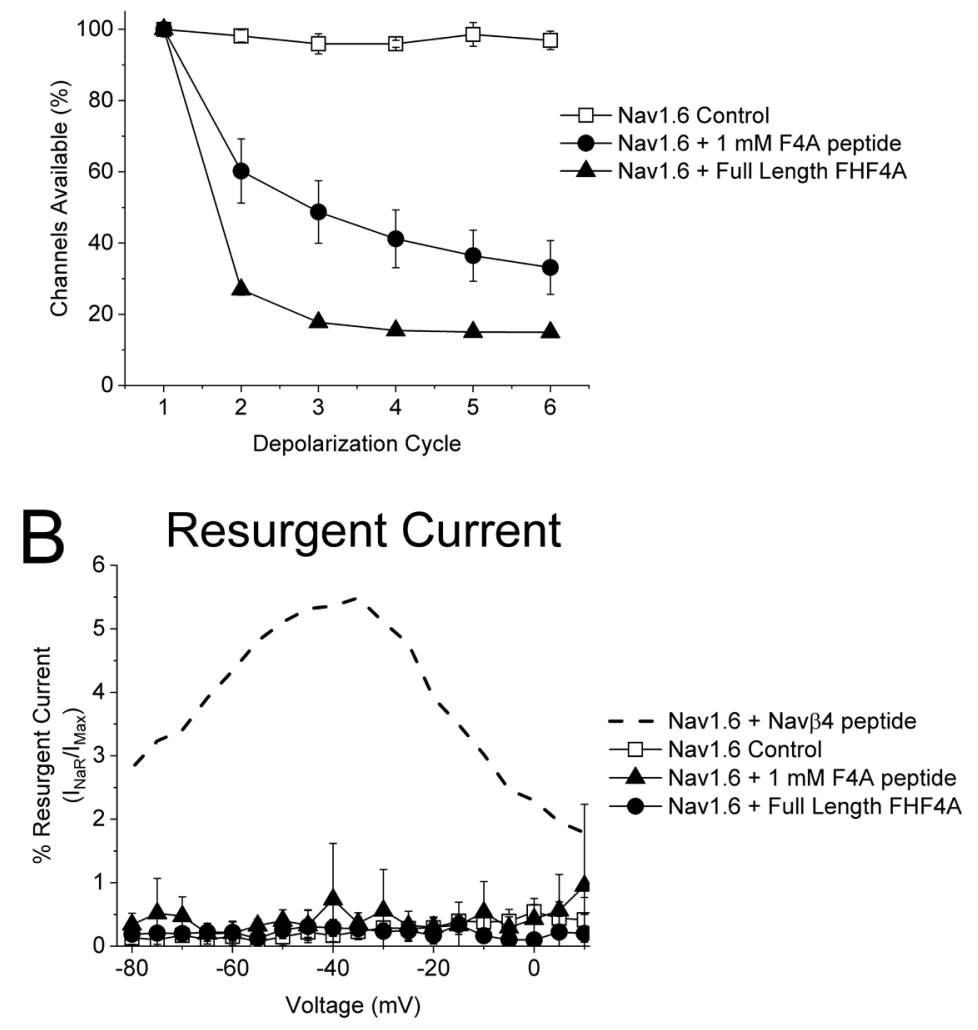